\title{
How influential are they? The role of parents, social support, attachment, and autonomy in college students' likelihood to experience social anxiety
}

\author{
Andrea M. Jones \\ West Virginia University
}

Follow this and additional works at: https://researchrepository.wvu.edu/etd

\author{
Recommended Citation \\ Jones, Andrea M., "How influential are they? The role of parents, social support, attachment, and \\ autonomy in college students' likelihood to experience social anxiety" (2009). Graduate Theses, \\ Dissertations, and Problem Reports. 2902. \\ https://researchrepository.wvu.edu/etd/2902
}

This Thesis is protected by copyright and/or related rights. It has been brought to you by the The Research Repository @ WVU with permission from the rights-holder(s). You are free to use this Thesis in any way that is permitted by the copyright and related rights legislation that applies to your use. For other uses you must obtain permission from the rights-holder(s) directly, unless additional rights are indicated by a Creative Commons license in the record and/ or on the work itself. This Thesis has been accepted for inclusion in WVU Graduate Theses, Dissertations, and Problem Reports collection by an authorized administrator of The Research Repository @ WVU. For more information, please contact researchrepository@mail.wvu.edu. 
How Influential Are They? The Role of Parents, Social Support, Attachment, and Autonomy in College Students' Likelihood to Experience Social Anxiety

\author{
Andrea M. Jones \\ Thesis submitted to \\ The Eberly College of Arts and Sciences \\ at West Virginia University \\ in partial fulfillment of the requirements \\ for the degree of
}
Master of Science
in
Psychology
Tracy L. Morris, Ph.D., Chair Steven A. Branstetter, Ph.D.
Amy Gentzler, Ph.D.
Department of Psychology
Morgantown, West Virginia 2009

Keywords: Parental Proximity, Parental Control, Parental Attachment, Social Anxiety, Social

Support, Autonomy 


\begin{abstract}
How Influential Are They? The Role of Parents, Social Support and Autonomy in College Students' Likelihood to Experience Social Anxiety
\end{abstract}

Andrea M. Jones

Previous research has found that parental control predicts social anxiety and is moderated by parental proximity, as measured by the amount of contact one has with their parent; however there have been no studies examining how levels of parental proximity may change over the course of a young adult's life. The purpose of the current study was to examine how variables previously associated with social anxiety change across a semester of college. The current study examined parental proximity, autonomy, social support and social anxiety at three points across the semester. Thirty-nine undergraduate students at West Virginia University participated in the study. It was hypothesized that as the semester progressed, reported levels of parental proximity would decrease, while autonomy and social support would increase as students assimilated more into the college community. To evaluate these hypotheses, a repeated measures analysis of variance was conducted. While results were in the predicted direction, there were no significant findings. As past research has found that levels of social anxiety were higher for those who maintained close proximity to their parents and whose parents were more controlling, it was hypothesized that the same would hold true for the current study. To test this hypothesis, a univariate analysis of variance was conducted; however, the results were not significant nor in the predicted direction. Implications and directions for future research are discussed. 


\section{Acknowledgments}

First, I would like to thank Tracy Morris, Ph.D. for all of her help with my thesis milestone and for her work as my research and academic advisor. She has truly been an advocate for me ensuring that I have the experiences needed to be successful in my career. Additionally, I would like to thank Steven Branstetter, Ph.D. for his guidance and willingness to help with statistical concepts. Also influential in my thesis project was Amy Gentzler, Ph.D., who was the final member on my committee. Finally, I would like to express my gratitude to the Alumni Fund of the Psychology Department at West Virginia University for their financial support of my project. 


\section{Table of Contents}

Title Page

$\begin{array}{lll}\text { Abstract } & \text { ii }\end{array}$

Acknowledgments

Table of Contents

List of Tables $\quad$ vi

Introduction and Literature Review 1

Development of Social Anxiety 1

Attachment Beyond Early Childhood 3

$\begin{array}{ll}\text { Autonomy } & 4\end{array}$

$\begin{array}{ll}\text { Social Support } & 5\end{array}$

Parental Warmth and Control in Children's Anxiety 5

$\begin{array}{ll}\text { Use of Self-Report Measures } & 7\end{array}$

$\begin{array}{lr}\text { Statement of Research Problem and Hypotheses } & 8\end{array}$

$\begin{array}{ll}\text { Method } & 9\end{array}$

Participants 99

Measures $\quad 9$

$\begin{array}{ll}\text { Procedure } & 15\end{array}$

$\begin{array}{ll}\text { Results } & 16\end{array}$

Correlations between Independent and Dependent Variables 17

Correlations among Phase I Parenting Variables and Symptom Change Scores 17

Longitudinal Examination of Independent and Dependent Variables 18

Social Anxiety as a Function of Parental Proximity and Control 18

Parenting Factors as Predictors of Symptom Variables 18 
Examination of the Proposed Hypotheses

Implications

Study Limitations

Directions for Future Research

References

Appendices

Tables 


\section{List of Tables}

1. Psychometric Properties of Independent and Dependent Variables 32

2. Participant Demographics 35

3. Descriptive Statistics for Dependent and Independent Variables at Phase I 38

4. Descriptive Statistics for Dependent and Independent Variables at Phase II 40

5. Descriptive Statistics for Dependent and Independent Variables at Phase III 42

6. Correlations of Independent and Dependent Variables at Phase I 44

7. Correlations of Independent and Dependent Variables at Phase II 47

8. Correlations of Independent and Dependent Variables at Phase III 50

9. Correlations among Phase I Parenting Variables and Phase III Symptom Variables 53

10. Correlations among Phase I Parenting Variables and Symptom Change Scores 54

11. Parenting Variables at Phase I as Predictors of Social Anxiety at Phase III 55

12. Parenting Variables at Phase I as Predictors of Anxiety at Phase III 56

13. Parenting Variables at Phase I as Predictors of Depression at Phase III 57 
How Influential Are They? The Role of Parents, Social Support and Autonomy in College Students’

\section{Likelihood to Experience Social Anxiety}

Social anxiety has been characterized as a negative reaction or aversion to social settings or performing in public that may include negative evaluative concerns, lack of confidence regarding one's ability to interact with others, avoidant behavior, heightened physiological response, and/or restricted functioning (Beidel \& Turner, 2007; Beidel, Turner, \& Dancu, 1985; Morris, 2001). Onset of clinically significant levels of social anxiety typically occurs during early to mid adolescence (Turner \& Beidel, 1989), when one is experiencing increased social demands, increased meta-cognitive skills, and selffocused attention (Morris, 2001). When adults are diagnosed with social anxiety, they often report having been shy and socially anxious throughout their entire life (Beidel \& Turner, 2007; Morris, 2001). In social settings, youth with social anxiety interact less with peers, initiate fewer interactions, and are less likely to receive positive outcomes from peers during interactions (Spence, Donovan, Brechman-Toussaint, 1999). Additionally, work by La Greca and Lopez (1998) examining high school students found that participants scoring higher in levels of social anxiety also reported lower levels of social support. No matter when the individual is diagnosed, social anxiety has been associated with substance use, academic impairment, school refusal, and comorbid internalizing symptoms such as depression, loneliness, and low self-esteem (Ginsburg, La Greca, \& Silverman, 1998; Kearney \& Silverman, 1990; see Greco \& Morris, 2005).

\section{Development of Social Anxiety}

Morris (2001) has presented a model for the development of social anxiety incorporating multiple etiological influences including temperament, family processes (attachment, parenting style, sociability, and modeling of fear), peer relationships, traumatic conditioning, cognitive biases, and social skills deficits. Within the realm of family processes, much has been written in the psychological literature on the importance of parent-child attachment. In infants and children, attachment figures function to provide

for physiological needs and emotional security (Bowlby, 1958, 1969). Several types of attachment have been identified — the most ideal being secure attachment. When an attachment figure in some way fails to 
provide emotional security and meet the physiological needs of the child, an insecure-ambivalent or insecure-avoidant attachment is likely to occur (Ainsworth, Blehar, Waters, \& Wall, 1978). Patterns of insecure attachment have been linked to future psychological problems, including anxiety (Erickson, Sroufe, \& Egeland, 1985; Kobak, Sudler, \& Gamble, 1991). Secure attachment contrasts with the various types of insecure attachment in that it functions to help children develop a basic sense of trust helping them to interact with and adapt to their environment (Sroufe, 1979). Attachment proves useful with social interactions in that it aids in the ability for one to form close relationships (Sroufe, 1979). Studies also have looked at parental psychopathology and found that anxious parents, particularly anxious mothers, are more likely to model avoidant behaviors that are associated with anxiety (e.g., Beidel \& Turner, 1997; Lieb, Wittchen, Höfler, Fuetsch, Stein, \& Merikangas, 2000; Rapee, 2001); however, limited work has been done looking at the influence of paternal psychopathology and the onset of childhood anxiety disorders, particularly social anxiety. Those studies examining this relationship often have included substantially fewer participants with social anxiety than any other anxiety disorder and have focused on mothers to the exclusion of fathers (e.g., Turner, Beidel, Roberson-Nay, 2005; Turner, Beidel, RobersonNay \& Tervo, 2003).

Extending past research looking solely at attachment, much work has been done in an attempt to understand childhood temperament's affect on attachment and the development of social anxiety. Here, the idea has been that more behaviorally inhibited children are more likely to experience an increased prevalence of social anxiety and other anxiety disorders (Biederman, Rosenbaum, Bolduc-Murphy, Faraone, Chaloff, et al., 1993; Biederman, Rosenbaum, Hirshfeld, Faraone, Bolduc, et al., 1990; Hirshfeld, Rosenbaum, Biederman, Bolduc, Faraone, et al., 1992; see Morris 2001) and to approach new situations with avoidance, restraint and distress (Garcia-Coll, Kagan, \& Reznick, 1984; Kagan, Reznick, \& Snidman, 1988; see Morris 2001). Additionally, several authors (e.g., Ginsburg, Siqueland, MasiaWarner and Hedtke, 2004; Masia \& Morris, 1998; Morris, 2001) have discussed how child temperament may interact with parent-child attachment processes in such a way as to increase the likelihood that the 
child will develop social anxiety disorder. These discussions have argued that parents often have behaviorally inhibited temperaments and/or psychopathology that are associated with an insecure attachment history. With regard to social anxiety, child temperament, family processes, performance inhibition, peer relationships, and social skills deficits all interact in such a way as to increase the likelihood that a child will develop social anxiety disorder (Morris, 2001).

In addition to research associated with social anxiety and other anxiety disorders in early childhood, there have been studies conducted examining factors that lead to continued anxiety in adolescence and extending into early adulthood (Armsden \& Greenberg, 1987; Bell, Avery, Jenkins, Feld, \& Schoenrock, 1985). This research has focused on parental warmth, parental control, continued attachment and proximity to parents as the child progresses through adolescence.

\section{Attachment Beyond Early Childhood}

Proximity to attachment figures is regulated by organized patterns of behavior (Armsden \& Greenberg, 1987). Armsden and Greenberg (1987) assert that a sense of security stems from the maintenance of this bond throughout one's life. They also state that anxiety, sadness, depression and anger occur when these attachment relationships are lost or strained. Furthermore, research has found that human beings are most well-adjusted when they are confident in the accessibility and availability of their attachment figure (Bowlby, 1969/1982). This attachment throughout the lifespan is evident through the behavior to seek close proximity to attachment figures. Although this disposition and the active seeking of close proximity to attachment figures decreases with age, "symbolic communication” such as letters and phone calls become increasingly important. Though with age there are changes in proximity seeking of attachment figures, expectations of future attachment figures (e.g., romantic partners) is based on earlier experiences with attachment figures and thus influences the manner in which they relate to others (Armsden \& Greenberg, 1987).

In addition, studies have found benefits to adolescents maintaining a close relationship even after having left their parents' house. One example is Bell and colleagues' study (1985) that sought to examine 
two relationships: (1) the association between the parent-child relationship and the child's level of social competence and (2) the association between the parent-child relationship and the quality of the child's peer relationships. Participants were 2,313 (1,328 females) freshmen enrolled at Texas Tech University and the University of Arizona. To measure the benefits of maintaining a close relationship with their parents, participants were given a measure of intrafamily affect asking them to rate the closeness of their relationship with their father, mother and siblings. They also were asked to complete eight measures examining social competence and the quality of their peer relationships. Analyses showed that secure parent-child attachment is associated with social competence and satisfying peer relationships during adolescence as well as during early childhood.

\section{Autonomy}

Bryant (1994) applied Erikson’s theory of psychosocial development to the idea that social support is essential for optimal functioning of children. Erikson's theory of psychosocial development posits that humans have a vital need for both social support and autonomy throughout their lifetime. His theory indicates that children should progress from being trusting of others, to becoming autonomous, to initiating, to being industrious, to having a committed identity. During these steps, the formation of connections to others as well as the ability to be autonomous from others is developing; therefore, the child must work to strike a balance between social connectedness and separateness. Bryant and Crokenberg (1980) elaborate on this theory by asserting that the development and experience of autonomy along with the presence of social relations appear crucially interrelated. Parents of children with anxiety disorders and of children scoring higher on anxiety inventories, however, are not as likely to grant their children autonomy or to be as accepting of their child as parents of non anxious controls (Greco \& Morris, 2002; Hudson \& Rapee, 2001; Wood, McLeod, Sigman, Hwang, \& Chu, 2003). In fact, studies have concluded that mothers of children with anxiety disorders and of children scoring high on measures of anxiety tend to be more negative and intrusive when their child is completing a task than parents of control children (e.g., Greco \& Morris, 2002; Hudson \& Rapee, 2001; Wood et al., 2003). In a 
review of recent articles published on the relation between parenting and childhood anxiety, Wood and colleagues (2003) also concluded that parents of children with anxiety are more controlling in conversational behavior than parents of non anxious controls. These findings support the idea that parenting factors such as low warmth, high control, and low granting of autonomy are positively associated with the development and maintenance of anxiety.

\section{Social Support}

Much research also has been done linking levels of social support with the development and maintenance of anxiety. In a community sample of 250 high school students (149 females) ranging in age from 15 to $18(M=17.04, S D=.91)$, La Greca and Lopez (1998) found that participants scoring higher in levels of social anxiety reported lower levels of social functioning, as measured by support from classmates and social acceptance. The same study also found there to be differences between males and females with regard to social support and functioning. Specifically, social anxiety was found to be more linked to females’ social functioning than males’ and that females experiencing higher levels of social anxiety are less likely to report high levels of support in their relationships. Past research also has found social support to moderate the relationship between depression, a highly comorbid construct with social anxiety, and negative life stressors experienced by college students such as academic affairs, male-female relationships and family matters (Cohen \& Hoberman, 1983). Additionally, research done by Larose and Boivin (1997) later found social support to mediate the relationship between parenting factors such as level of attachment and personal adjustment, as measured by inventories assessing interaction anxiety and loneliness, in high school students. While social support has been found to be related to levels of social anxiety, adjustment and parenting factors in past research, little longitudinal research has been done examining these relationships.

\section{Parental Warmth and Control in Children's Anxiety}

Research examining parental warmth and control has found that optimal child development occurs in families that exhibit high levels of warmth and support, are consistent with behavioral 
expectations and consequences, and accept individuality and psychological autonomy (Baumrind, 1971, 1989). In contrast, children with anxiety disorders often come from families that are less open to expression, exhibit heightened levels of conflict, and who exhibit lower levels of family cohesion, support and democracy in decision making (Stark, Humphrey, Cook, \& Lewis, 1990). Wood and colleagues (2003) observed this same finding in a meta-analysis of 2,699 adolescents aged 11 to 20 all drawn from community samples. Here, parental warmth was described as a "general parenting approach characterized by interactional warmth and responsiveness, as well as emotional and behavioral involvement in children’s lives and activities.” Examples of how parents can exhibit warmth include accepting their children's feelings and behaviors, engaging in active listening and praise, and the use of reflection (Wood et al., 2003). More supportive parents are also more inclined to help their child to gain problem solving skills and coping competencies (Krohne \& Hock, 1991). By contrast, control was defined as “excessive regulation of children's activities and routines, autocratic parental decision making, overprotection, or instruction to children on how to think and feel” (Wood et al., 2003). Those reporting more parental nurturance and warmth were more likely to be rated by their parents and teachers as less anxious than those reporting less parental nurturance and warmth; however, those reporting high parental control were more likely to have experienced childhood anxiety when compared to the onset of anxiety in children whose parents were more supportive. This relationship has been observed in several studies finding that parents of children scoring high in levels of anxiety exhibit the tendency to intervene in their children’s tasks (e.g., Barlow, 1991; Greco \& Morris, 2002; Krohne \& Hock, 1991; Rapee, 1997).

Chorpita (2001) asserts that this history of a lack of control may put individuals at a heightened risk to experience "chronic negative emotional states,” as their lack of control is associated with psychological vulnerability. Parental control does not seem to stop having an effect once a child is older, rather it has been found to predict social anxiety in college students. This was examined in a study by Anhalt and Morris (2008) that found parental control to remain a significant predictor of anxiety even into the college years. Chrystan (2005) expanded upon Anhalt and Morris’ (2008) study by examining 
whether college students' proximity to their parents had an effect on the relationship between parental control and social anxiety. To do so, Chrystan (2005) administered a battery of questionnaires and inventories to 400 students (301 females) enrolled in psychology courses at West Virginia University. This study found that college students, who were close in proximity to their controlling parents, experienced a positive association between parental control and anxiety. Chrystan (2005) also found that high parental proximity is beneficial when parents are low in control but detrimental when parents were high in control. Finally, autonomy was found to predict social anxiety when maternal and paternal parenting variables were controlled. This finding is unique because it may explain how parental control and proximity are related to social anxiety. Stated another way, autonomy may be the mechanism that drives the relationship between parental control and social anxiety.

\section{Use of Self-Report Measures}

The relation of parenting factors with the onset and maintenance of childhood anxiety is ideally measured through observational studies. Observational studies are advantageous in that they do not rely on the accuracy of retrospective memory nor do they have the age limitations that self-report measures possess. However, research using self-report measures to examine parenting variables (e.g., Anhalt \& Morris, 2008; Massey, 2000) has yielded similar results to those using observational methods (e.g., Greco \& Morris, 2002; Hudson \& Rapee, 2001; Hudson \& Rapee, 2002; Krohne \& Hock, 1991). Research also has found child and parent reports of parenting behaviors to be more congruent than common cultural congruence and that congruence improves with child development and age (Lanz, Scabini, Vermulst, \& Gerris, 2001). Congruence, for the purposes of the study was defined as "within-dyad similarity regarding specific behaviors, norms and values, personality characteristics, cognitive development or perceptions.” Participants in the study were asked to rate their own family members on measures of parent behavior and then to rate non family members on measures of parenting behaviors. Results showed that more congruence was found between family members than nonkin and that congruence ratings improved as the child aged. Furthermore, in a review of past research on parenting variables, Hudson and Rapee (2001) 
found that both observational and self-report, questionnaire measures were equally supportive of the link between parenting factors such as control and anxiety.

\section{Statement of Research Problem and Hypotheses}

Past work by Chrystan (2005) found that parental proximity moderates the relationship between parental control and social anxiety such that students high in parental proximity with highly controlling parents were more likely to be highly socially anxious, whereas students high in parental proximity with low controlling parents exhibited low social anxiety. Chrystan also found there to be a significant, negative correlation between autonomy as measured by the Revised Sociotropy-Autonomy Scale and social anxiety as measured by the Social Phobia and Anxiety Inventory. The present study sought to expand Chrystan's work by examining how variables implemented with the development of social anxiety change over time. The current study examined parental proximity, autonomy, social support and social anxiety at three points during a college semester. Additionally, the current study investigated correlations between social anxiety and parenting variables including trust, communication, alienation, and care. Finally, correlations among social anxiety, social support, and autonomy were examined.

It was hypothesized that as the semester progressed, reported levels of parental proximity would decrease, while autonomy and social support were expected to increase as students assimilated more into the college community. Additionally, it was hypothesized that there would be a significant, negative correlation between social anxiety and the following parenting variables: trust, communication, alienation, and care. It also was hypothesized that there would be a significant, negative correlation between social anxiety and social support and between social anxiety and autonomy. Finally, as Chrystan (2005) found that levels of social anxiety were higher for those who maintained high proximity to their parents and whose parents were highly controlling, it was hypothesized that this finding would hold true for the current study. 


\section{Method}

\section{Participants}

Thirty-nine students (aged 18-27) from undergraduate psychology classes at West Virginia University completed all three phases of the study; however, there were 149 participants who completed phase I. Participants were recruited through Sona, an experiment management system for online research, for participation in three phases of the study. Notification for participation in phases II and III occurred by email and were managed through Sona. For their participation in the study, participants were compensated in the form of extra credit. Students completing all three testing sessions were entered into a drawing for a cash award.

\section{Measures}

Demographic Questionnaire. Participants completed a demographic questionnaire to obtain data about participant gender, age, ethnicity, relationship status, and status in college (Appendix A). The questionnaire also assessed who participants considered to be their primary maternal and paternal figure, the length of time they lived with their primary caregiver and mental health concerns affecting their primary caregiver. To evaluate the degree of parental proximity each participant had to their primary caregiver, the questionnaire also asked how far away West Virginia University is from their caregivers’ residence and the participants' reasoning for choosing to attend WVU. Psychometric properties for all subsequently described inventories are listed in Table 1.

Continued Attachment Scale—Parent Version (CAS; Armsden and Greenberg, 1987). The CAS is a six-item questionnaire that asks participants to endorse items about their relationship with their caregiver on a 5-point Likert scale. Participants are asked to respond to the scale once with respect to their maternal caregiver and once with respect to their paternal caregiver. Questions included on the scale assess the degree to which respondents think about their caregiver, the degree to which participants disclose information to their caregiver about their life, as well as the amount of contact the participant has with their caregiver. The scale was originally developed for the study of divorce but also has been used to 
look at continued parental attachment of adolescents during the transition to college, where continued attachment is defined as a "preoccupation, longing, concern about, and desire for contact with the attachment figure” (Berman \& Sperling, 1991).

To evaluate the psychometric properties of the scale, Heiss, Berman, and Sperling (1994) administered the scale to 216 (101 females) college students enrolled in introductory psychology courses with a mean age of $19.8(S D=4.8)$. The scale was found to have high concurrent validity by comparing it with the Parental Bonding Instrument, The Attachment Style Inventory, The Inventory of Parent and Peer Attachment, and The Parental Attachment Questionnaire. Heiss, Berman, and Sperling found there to be high internal consistency with a Chronbach’s Alpha of .74 for mother ratings and a Chronbach’s Alpha of .80 for father ratings. Test-retest reliability for a four week period was also found to be high (.85 for mothers and .82 for fathers).

Parental Bonding Instrument (PBI; Parker, Tupling \& Brown, 1979). The PBI is a 25-item (12 Care and 13 Protection items) self-report measure that assesses children’s “retrospective perceptions of parent behavior” through the use of a 3-point Likert scale yielding a maximum score of 36 for the care items and 39 for the protection items (Parker, Tupling, \& Brown, 1979). Parker, Tupling, \& Brown assert that the scale is useful for the consideration of optimal parental bonding and to examine the influence of parental distortions on psychological and social functioning in participants. The scale was originally standardized using 150 participants (79 females) that included 65 medical students, 43 psychiatric nurses, 13 technical college students, and 29 parents of children at a local score. The age of participants ranged from 17 to 40 with a mean age of 25 years. Data for 150 mothers and 148 fathers was factor analyzed revealing the scale to have two factors-Care and Protection—accounting for $28 \%$ and $17 \%$ of the variance, respectively. The PBI was shown to have a high 3 week test-retest reliability with a Pearson correlation coefficient of .76 ( $\mathrm{p}<.001)$ for the Care scale and a .63 Pearson correlation coefficient $(\mathrm{p}<$ .001) for the Protection scale. Concurrent validity was evaluated by comparing two raters' (the first and second authors) scores of participant Care and Protection with the Care and Protection scale scores of 65 
participants. For Care, the correlation between the scale and raters was high with a .77 $(\mathrm{p}<.001)$ correlation between Rater 1 and the scale and a .78 correlation $(\mathrm{p}<.001)$ for Rater 2 . Concurrent validity scores were found to be moderate for the Protection scale with the correlation between Rater 1 and the scale being .48 $(\mathrm{p}<.01)$ and the correlation for Rater 2 being $.51(\mathrm{p}<.001)$. The inter-rater reliability for the Care scale was $.85(\mathrm{p}<.001)$ and $.69(\mathrm{p}<.01)$ for the Protection scale. In addition to research revealing good validity and reliability of the PBI, a review of the PBI over a span of 10 years and across several populations revealed that the factorial structure of the PBI is stable in both clinical and non clinical populations, test-retest reliability is both high and stable over months, and that there is moderate consistency of scores for up to 10 years (Parker, 1990).

Inventory of Parent and Peer Attachment (IPPA; Armsden \& Greenberg, 1987). The IPPA is a 53 item self-report inventory developed to examine attachment in late adolescence by determining the importance of various attachment figures for psychological well-being in adolescence and early adulthood. Attachment relationships are evaluated based on the respondents’ frequency endorsements of items on three scales—i.e., trust, communication, and alienation—using a 5-point Likert scale. It is important to note that higher scores on the trust and communication scales are reflective of high attachment, while higher scores on the alienation scale are associated with a lack of parental alienation. Psychometric properties were evaluated through the examination of responses made by 179 participants drawn from two undergraduate institutions. Both the parent and peer scales were found to have high internal validity with the parent scale demonstrating a Chronbach’s Alpha of .91, .86, and .86 for the trust, communication, and alienation scales, respectively. The peer scales revealed a Chronbach’s Alpha score of .91, .87, and .72 for the trust, communication, and alienation scales, respectively. Concurrent validity was measured by comparing scores on the IPPA with scores on the Family Environment Scale (FES), the Tennessee Self-Concept Scale (TSCS). Evaluation of these scales revealed the FES Cohesion and Expressiveness scales to correlate .56 and .52, respectively with the IPPA. Finally, the IPPA demonstrated somewhat stronger convergent validity with the TSCS with a correlation of .78. 
Social Phobia and Anxiety Inventory (SPAI; Turner, Beidel, Dancu, \& Stanley, 1989). The SPAI is a 45-item, self-report inventory consisting of two subscales: Social Phobia and Agoraphobia. The Social Phobia subscale contains 32 items with several containing multiple parts, while the Agoraphobia subscale contains 13 items (Clark, Turner, Beidel, Donovan, Kirisci \& Jacob, 1994). Collectively, the SPAI assesses specific somatic symptoms, cognitions, and behavior across a range of potentially fearproducing situations and are to be endorsed by participants on a 7-point Likert scale (Turner, et al.). The SPAI was originally standardized with 182 participants from introductory psychology classes. Participants included 123 individuals scoring low on measures of social anxiety and 59 individuals scoring high on measures of social anxiety. Psychometric properties for the scale were strong with a two week test-retest reliability of .87 $(\mathrm{p}<.01)$ for males and .85 for females $(\mathrm{p}<.01)$ and a Chronbach’s Alpha of .96 for the Social Phobia Scale and .85 for the Agoraphobia Scale. Discriminant validity was also proven to be very high as $76 \%$ of people with social phobia, $75.6 \%$ of people with agoraphobia, and 38.9\% of people with obsessive compulsive disorder were identified using the scale (Turner et al.). Research by Osman, Barrios, Aukes, and Osman (1995) examined the psychometric properties of the SPAI in college students and found there to be good support for concurrent validity. A correlational analysis revealed there to be positive and significant correlations of the SPAI-Social Phobia subscale with the Social Avoidance and Distress Scale, the MMPI-2 Social Avoidance Subscale, and the Fear Questionnaire-Social Anxiety Subscale. Correlational analyses also revealed there to be good concurrent validity for the SPAI-Agoraphobia subscale in that there was a significant and positive relationship between the Fear Questionnaire Agoraphobia subscale and the SPAI-Agoraphobia subscale.

Revised Sociotropy-Autonomy Scale (SAS-R; Clark, Steer, Beck, \& Ross, 1995). The SAS-R is a 59 item, self-report scale that measures the degree to which participants value interpersonal relationships versus autonomy. Participants answer each statement based on the extent to which they feel the statement describes themselves. The scale was revised in an attempt to refine the psychometric properties of the previous SAS scale consisting of 93 items. In order to construct the revised version of the inventory, the 
first edition was administered to 894 first-year students (577 females). Once the participants completed the inventory, a principal factor analysis was performed revealing only 59 of the 93 items to load on three factors—sociotropy, solitude, and independence. These 59 items were retained and administered to a second group of 1,015 psychology students (618 females) to measure the convergent and divergent validity of the 59 item scale. Convergent and divergent validity were evaluated and found to be good using the Beck Depression Inventory (BDI), Depressive Experiences Questionnaire (DEQ), Multidimensional Perfectionism Scale (MPS), Interpersonal Orientation Scale (IOS), Social and Emotional Loneliness Scale (SELS), and the Personality Style Inventory (PSI). The SAS Sociotropy subscale correlated highly with the DEQ dependency and self-criticalness scales, the IOS subscales measuring affiliation and motivation, the PSI sociotropy subscale, and the BDI. The SAS Solitude subscale correlated with the MPS socially prescribed perfectionism scale, DEQ self-criticalness subscale, the IOS attention subscale, loneliness as measured by the SELS subscales, the autonomy subscale of the PSI and to the BDI. Finally, the SAS independence subscale correlated with the DEQ Self-efficacy subscale and had a slight association with the MPS Self-Oriented Perfectionism subscale and the autonomy subscale of the PSI.

Interpersonal Support Evaluation List (ISEL; Cohen \& Hoberman, 1983). The ISEL is a 48 item, self-report inventory designed to assess the perceived availability of potential social resources. Included within the scale are four 12-item subscales: the "tangible” subscale was included to measure perceived availability of material aid, the "appraisal” subscale to assess the perceived availability of someone with whom to discuss one's problems, the "self-esteem” subscale measuring the perceived availability of favorable comparisons when comparing one's self to others, and the "belonging” subscale designed to measure the perceived availability of individuals with whom one can engage in various activities. Participants respond to items such as, "I know someone at school or in town who would bring my meals to my room or apartment if I were sick (Tangible Subscale)," "I belong to a group at school or in town that meets regularly or does things together regularly (Belonging Subscale)," "I know someone who I see 
or talk to often with whom I would feel perfectly comfortable talking about any problems I might have meeting people (Appraisal Subscale)," and “Most of my friends have not adjusted to college as easily as I have (Self-esteem Subscale)" by indicating whether each statement is "probably true” or "probably false.” Within each scale, six of the items are written such that a "probably true” response indicates support, while the remaining items are written such that a "probably false” response indicates support. Standardization for the self-report measure was performed using 63 students from an original sample of 70 (43 females) drawn from college students enrolled in an introductory social psychology class at the University of Oregon. The scale has been demonstrated to have good internal reliability with a total scale Chronbach’s Alpha of .77, .71 for the Tangible subscale, .75 for the Belonging subscale, .60 for the Selfesteem subscale, and .77 for the Appraisal subscale. The scale also was found to have moderate concurrent validity with the Inventory of Socially Supportive Behaviors, $\mathrm{r}=.46, p<.001$.

Beck Anxiety Inventory (BAI; Beck, Epstein, Brown, \& Steer, 1988). The BAI is a 21-item, selfreport measure designed to measure the severity of anxiety symptoms endorsed by psychiatric populations. Respondents are to rate the degree of distress experienced on each item over the past week using a 4-point Likert scale. Standardization of the scale consisted of 160 subjects with 40 carrying the diagnosis of Major Depressive Disorder, 18 with Dysthymic disorder and atypical depression, 18 presenting with Agoraphobia and panic attacks, 18 with generalized anxiety disorder, 18 with social and simple phobia, and 16 with miscellaneous non-anxiety and non-depression disorders such as academic problems and adjustment disorders. Psychometric properties were also evaluated using the same participants and were proven to be strong. Internal consistency was good with a Chronbach’s Alpha of .92 and item-total correlations ranging from .30 to .71 with a median of .60. The one week test-retest reliability $(\mathrm{N}=83)$ was also strong with a Pearson correlation coefficient of .75. Factor analyses revealed two factors - the first being somatic symptoms and second being subjective anxiety and panic symptoms. Finally, the scale was shown to have good convergent and divergent validity. Convergent validity was measured evaluating correlations with the Hamilton Anxiety Rating Scale-Revised (HARS-R) and the 
Cognitive Checklist-Anxiety (CCL-A), while divergent validity was examined using the Cognitive Checklist-Depression (CCL-D), the Hopelessness Scale (HS) and the Hamilton Rating Scales for Depression-Revised (HRSD-R).

Beck Depression Inventory II (BDI-II; Beck, Steer, \& Brown, 1996). The BDI-II is a 21-item, self-report measure designed to measure the severity of depressive symptoms. To do so, respondents are asked to rate items on a 4-point Likert scale.

The second version of the BDI was developed after the first edition was found to have low content validity evaluating only 6 of the 9 DSM diagnostic criteria for depression. The present version was developed to increase the number of symptoms from the DSM-IV evaluated by the scale as well as to evaluate increases in appetite, weight, and sleep—-the first version only measured decreases.

Psychometric properties of the second edition were evaluated by Dozois, Dobson and Ahnberg (1998) using 1,022 undergraduate psychology students (67\% female) with an average age of 21 (SD = 4.47). After participants completed the measure, factor analysis revealed two factors with the first being a cognitive-affective dimension measuring past failure, worthlessness, self-dislike, pessimism, selfcriticalness, indecisiveness, guilty feelings, suicidality, punishment feelings and sadness. The second factor was a somatic-vegetative symptom dimension and measured changes in sleep, fatigue, loss of energy, irritability, agitation, loss of interest in sex, loss of interest, loss of pleasure, and changes in appetite. Internal consistency for the scale was proven to be strong with a Chronbach’s Alpha of .91. Steer and Clark (1997) also found the measure to have high convergent validity with the SAS-R.

\section{Procedure}

Upon entering Sona, an online research participation system, students were presented with an informed consent form (Appendix B). Consent was indicated by their agreeing to continue on to survey inventories. Each participant was presented with a series of inventories to complete and had the option of skipping any question which they desired not to answer. Inventories were presented from least to most invasive; however, inventories inquiring about parenting variables were presented together such that 
participant response was not influenced by inventories assessing autonomy or social support. The study took place over the course of three sessions. The first session was open at the beginning of the semester, the second mid-way through the semester, and third at the end of the semester. Participants were notified via email when they were to complete each phase of the study.

\section{Results}

Demographic characteristics of the 39 participants (72\% female) are listed in Table 2. The majority of participants were college freshmen (33\%) followed by sophomores (31\%), juniors (21\%), and seniors (15\%). Reflective of university demographics from which the sample was drawn, the majority of participants (87\%) were Caucasian (Non Hispanic). Of the 39 participants, 97\% stated that they consider their biological mother to be their primary maternal figure, while $87 \%$ of participants stated that they consider their biological father to be their primary paternal figure. Additionally, 54\% of participants stated that they have lived with their primary maternal figure for 16-18 years with an additional 31\% stating that they have lived with their primary maternal figure for 19-20 years. Regarding the length of time participants have lived with their primary paternal figure, $41 \%$ of participants stated that they lived with their father for 16-18 years, while $26 \%$ stated that they have lived with their primary paternal figure for 19-20 years. The majority of participants did not endorse having any knowledge of maternal (80\%) or paternal (82\%) mental health diagnoses. Finally, 36\% of participants stated that WVU is 1-3 hours away from their home, while $26 \%$ of participants stated that WVU is 3-6 hours away from their home.

No significant differences were found in participants' SPAI Difference scores based on their response to the following demographic variables: gender, age, ethnicity, status in college, primary maternal figure, primary paternal figure, the amount of years the participant has lived with their maternal figure, the amount of years the participant has lived with their paternal figure, maternal mental health, paternal mental health, relationship status, the distance of WVU from their home, why they chose WVU, maternal education level, or paternal education level. 
Table 3 contains a list of descriptive statistics for the main dependent and independent variables at phase I. Tables 4 and 5 display descriptive statistics for the main independent and dependent variables at phase II and III respectively.

\section{Correlations between Independent and Dependent Variables}

Table 6 contains Pearson product-moment correlations between the study's independent and dependent variables at phase I. Tables 7 and 8 list Pearson product-moment correlations between the study's independent and dependent variables at phase II and III, respectively. Although there were no hypotheses made regarding associations among the study’s independent and dependent variables and the BDI-II and BAI, there were several significant correlations, which are listed in Tables 6-8. Additionally, Table 9 contains Pearson product-moment correlations among parenting variables at phase I (e.g., PBI and IPPA) and symptom variables at phase III (e.g., SPAI Difference, BDI-II, and BAI). Most notably, maternal and paternal alienation at phase I were significantly associated with social anxiety, general anxiety, and depression at phase III and both maternal and paternal communication were associated with social anxiety.

Correlations among Phase I Parenting Variables and Symptom Change Scores

Change scores for each of the symptom variables were calculated by subtracting phase III scores from phase I scores. Pearson product-moment correlations were then conducted between change scores and the phase I parenting variables (See Table 10). Notably, paternal and maternal overprotection, paternal alienation, and a lack of paternal trust were associated with increasing levels of general anxiety across the semester. Post hoc power analyses revealed the power to detect significant effects was .73, .68, .62 , and .62 respectively. Impaired maternal communication was associated with increasing levels of social anxiety across the semester. Power to detect a significant correlation between maternal communication and social anxiety symptom change scores was .70. 


\section{Longitudinal Examination of Independent and Dependent Variables}

A repeated measures analysis of variance was conducted to evaluate change across the three phases for parental proximity, autonomy, social support and social anxiety. It was expected that social anxiety and parental proximity would significantly decrease over the course of the semester. While these variables changed in the expected direction, decreases across the three phases were not statistically significant. In contrast to the aforementioned variables, it was expected that autonomy and social support would increase across the three phases. Although not statistically significant, autonomy decreased across the three phases, while social support increased.

\section{Social Anxiety as a Function of Parental Proximity and Control}

Prior to evaluating whether social anxiety differed as a function of parental proximity and control, regression analyses were conducted to determine whether parental proximity and parental control at phase I significantly predicted social anxiety at phase III. These analyses revealed that maternal $(B=-.96, p<$ $.05)$ and paternal $(B=-.79, p<.05)$ proximity at phase I significantly predicted social anxiety at phase III; however, parental control at phase I was not a significant predictor of social anxiety at phase III. Examination of the interaction terms (e.g., maternal control X maternal proximity and paternal control X paternal proximity) revealed that the interaction term also was not a significant predictor of social anxiety. Therefore, the current study did not find that social anxiety scores differed as a function of parental control and proximity.

\section{Parenting Factors as Predictors of Symptom Variables}

Regression analyses with parenting variables (e.g., PBI and IPPA) from phase I as predictor variables and social anxiety at phase III as the dependent variable were conducted to determine the predictive ability of parenting style and attachment for early adult social anxiety (See Table 11). Significant predictors of social anxiety at phase III controlling for social anxiety at phase I include: PBI- 
F/Care $(B=-.43, p<.05)$, IPPA-M/Communication $(B=-.72, p<.01)$, IPPA-F/Communication $(B=-$ $.54, p<.05)$, and IPPA-F/Alienation $(B=-.52, p<.05)$.

There were no hypotheses made regarding the predictive ability of parenting variables for anxiety; however, there were several parenting variables assessed at phase I that were statistically significant predictors of anxiety at phase III (See Table 12). Examination of regression analyses investigating predictive relationships between parenting variables and symptom variables indicate that PBI-F/Care $(B=.66, p<.05)$, IPPA-F/Trust $(B=-.46, p<.05)$, IPPA-F/Communication $(B=-.42, p<$ .05), IPPA-M/Alienation $(B=-1.00, p<.05)$ and IPPA-F/Alienation $(B=-.57, p<.01)$ significantly predict anxiety. The predictive ability of these phase I parenting variables was statistically significant even after controlling for anxiety at phase I. Similarly, there were no hypotheses made regarding the predictive ability of phase I parenting variables for depression at phase III; however, Table 13 contains the results of regression analyses conducted to evaluate the predictive ability of parenting variables at phase I for depression at phase III. That there were no phase I parenting variables that significantly predicted phase III anxiety when controlling for phase I anxiety suggests that phase I anxiety explains the majority of variance in phase III anxiety.

\section{Discussion}

\section{Examination of Proposed Hypotheses}

Contrary to the proposed hypotheses, decreases in parental proximity and social anxiety and increases in social support were not statistically significant; however, changes in these variables were in the predicted direction. That changes were in the predicted direction but not statistically significant may be due to low statistical power. With a larger sample, it is predicted that significant decreases in these variables would be observed. In addition, these variables had high test-retest correlations, suggesting that these constructs are relatively stable across three months. Finally, larger sample sizes are required to evaluate changes in autonomy that were not in the predicted direction nor statistically significant. 
Also inconsistent with the proposed hypotheses, was that social anxiety did not significantly differ as a function of parental proximity and control. As with the variables for which change across the semester was expected, there was not sufficient power to detect differences in social anxiety as a function of high and low parental proximity or high and low parental control.

Contrary to the current study’s hypotheses, the SPAI Difference score was significant and positively correlated with autonomy, as measured by the SAS/Independence scale; however, this was only found to be true at phase II. More power is needed to draw accurate conclusions about social anxiety's relation with autonomy. Also inconsistent with the study's hypotheses, the SPAI difference score was not significantly correlated with levels of social support at any of the study's phases. This too, should be investigated in future studies with more power to detect significant correlations.

Past research suggesting that parenting variables are important in the development of social anxiety was supported by significant correlations between the SPAI Difference score and parenting variables such as communication, alienation, continued attachment, and care. Additionally, correlations between maternal communication and change scores for the SPAI Difference score indicate that high levels of communication between mother and child are associated with decreases in social anxiety across a three month period. This finding is especially promising as a post hoc power analysis found that there was only a $70 \%$ chance of detecting an effect if one truly existed in the population. Future studies with more power to detect significant findings may find an even larger correlation between maternal communication and change scores for the SPAI Difference score.

Finally, although not included in the original hypotheses, there were a number of significant correlations among the BDI-II, BAI and the study's independent and dependent variables. These findings support past research suggesting that social support is a protective factor against the development of depression and anxiety. The findings also support past research suggesting that parenting variables such as communication, trust, alienation, and warmth serve as protective factors against the development of depression and anxiety. Additionally, correlations between the BAI change score and paternal and 
maternal protection, paternal trust, paternal communication, and parental alienation suggest that parenting variables may serve as risk factors for increasing anxiety across a three month period. Finally, correlations involving the BDI-II and the BAI suggest that depression and general anxiety are both correlated with social anxiety.

\section{Implications}

Due to the study's limited statistical power, no definitive conclusions can be made regarding the proposed hypotheses; however it is important to note that several hypotheses were in the predicted direction. This bodes well for future research with larger samples. Strong and significant correlations among parenting variables, social support, depression, anxiety, and social anxiety suggest that targeting parenting variables and working to increase levels of social support may be influential in helping to prevent and treat anxiety disorders and depression. Significant correlations between symptom change scores and parenting variables suggest that parenting variables may also be influential in treating individuals already diagnosed with a mental health disorder.

\section{Study Limitations}

When considering the results of the current study, it is important to note the sample size, which affected the power to detect significant changes in autonomy, parental proximity, social support, and social anxiety. Limited power also affected the ability to find significant associations in the relationship between high and low parental control and social anxiety as well as high and low parental proximity and social anxiety. Such limited power increases the chances of type II errors.

Although past research was provided demonstrating that self-report measures have in the past allowed us to draw similar conclusions about social anxiety and parenting behaviors (e.g., Anhalt \& Morris, 2008; Massey, 2000) as research utilizing observational methods, (e.g., Greco \& Morris, 2002; Hudson \& Rapee, 2001; Hudson \& Rapee, 2002; Krohne \& Hock, 1991) it is still preferable to rely on observational data rather than self-report. The use of observational data is advantageous in that researchers do not have to rely on the accuracy of retrospective memory. 
The method for which participants were selected for the study also should be considered. Participants were drawn from psychology courses at WVU. Participation in research allowed these participants the opportunity to gain extra credit points that could be applied toward their final grade. However, it should be noted that participation in research was not the only opportunity for students to gain extra credit points; rather, students could also gain extra credit by reading articles and taking quizzes on those articles. The latter required much less effort and time. Participation in the current study required participation in three phases of data collection across the entire semester, which appears to have drastically lowered participation rates when compared to other single-occasion online studies. Finally, it should be noted that participants were not monitored while completing inventories for the current study; rather, they had the capability to complete inventories anywhere they had internet access. As such participants may have been distracted by events occurring in their environment.

\section{Directions for Future Research}

So that the development of social anxiety as a function of parenting variables is better understood, it is important that longitudinal research continue to be conducted. Understanding the development of social anxiety will aid in the development of preventative and treatment programs. Additionally, it is also important to understand how levels of social support and autonomy are related to social anxiety, which may also be an avenue to explore for those creating preventative and treatment programs for social anxiety. Moreover, these relationships should be examined across developmental ages, such that a closer examination of these variables is conducted during early and middle childhood as well as during adolescence. Finally, there is a need for more research, such as the current study, that examines both maternal and paternal variables so that the effects of each parent can be explored. Future research should also evaluate whether the effects of deficits in parenting variables such as warmth and excesses in parenting variables such as control can be corrected by appropriate levels of warmth and control in the coparent. 


\section{References}

Ainsworth, M. D. S., Blehar, M. C., Waters, E., \& Wall, S. (1978). Patterns of attachment: A psychological study of the strange situation. Hillsdale, NJ: Lawrence Erlbaum.

Armsden, G. C., \& Greenberg, M. T. (1987). The inventory of parent and peer attachment: Individual differences and their relationship to well-being. Journal of Youth and Adolescence, 16, 427-454.

Anhalt, K, Morris, T. L. (2008). Parenting characteristics associated with anxiety and depression: Exploring the contribution of multiple factors. Journal of Early and Intensive Behavioral Interventions, 5, 122-137.

Barlow, D. H. (1991) Disorders of emotion. Psychological Inquiry, 2, 58-71.

Baumrind, D. (1971). Harmonious parents and their preschool children. Developmental Psychology, 4, 99-102.

Baumrind, D. (1989). Rearing competent children. In W. Damond (Ed.), Child development today and tomorrow (pp. 349-378). San Francisco: Jossey-Bass/Pfeiffer.

Beck, A. T., Epstein, N., Brown, G., Steer, R. A. (1988). An inventory for measuring clinical anxiety: Psychometric properties. Journal of Consulting and Clinical Psychology, 56, 893-897.

Beck, A. T., Steer, R. A., \& Brown, G. K. (1996). Manual for Beck Depression Inventory-II. San Antonio. TX: Psychological Corporation.

Beidel, D. C., \& Turner, S. M. (1997). At risk for anxiety: I. Psychopathology in the offspring of anxious parents. Journal of the American Academy of Child and Adolescent Psychiatry, 36, 918-926.

Beidel, D. C., \& Turner, S. M. (2007). Shy children, phobic adults: Nature and treatment of social phobia. $2^{\text {nd }}$ Edition. Washington, DC: American Psychiatric Association.

Beidel, D.C., Turner, S.M., Dancu, C. V. (1985). Physiological, cognitive, and behavioral aspects of social anxiety. Behaviour Research and Therapy, 23, 109-117.

Bell, N. J., Avery, A. W., Jenkins, D., Feld, J., Schoenrock, C. J. (1985) Family relationships and social competence during late adolescence. Journal of Youth and Adolescence, 14, 109-119. 
Berman, W. K., \& Sperling, M. B. (1991). Parental attachment and emotional distress in the transition to college. Journal of Youth and Adolescence, 20, 427-440.

Biederman, J., Rosenbaum, J. F., Bolduc-Murphy, E. A., Faraone, S. V., Chaloff, J., Hirshfeld, D. R., \& Kagan, J. (1993). A 3-year follow-up of children with and without behavioral inhibition. Journal of the American Academy of child and Adolescent Psychiatry, 32, 814-821.

Biederman, J., Rosenbaum, J. F., Hirshfeld, D. R., Faraone, S. V., Bolduc, E. A., Gersten, M., Meminger, S. R., Kagan, J., Snidman, N., \& Reznick, J. S. (1990). Psychiatric correlates of behavioral inhibition in young children of parents with and without psychiatric disorders Archives of General Psychiatry, 47, 21-26.

Bowlby, J. (1958). The nature of the child's tie to his mother. International Journal of Psychoanalysis, 39, 1-23.

Bowlby, J. (1969/1982). Attachment and loss: Vol. 1. New York: Basic Books.

Bryant, B. K. (1994). How does social support function in childhood? In Nestman, F., Hurrelmann, K. (Eds.) Social networks and social support in childhood and adolescence. Oxford, England: Walter De Gruyter, pp. 23-35. [Chapter]

Bryant, B. K. \& Crockenberg, S. (1980). Correlates and dimensions of prosocial behavior: Female siblings with their mothers. Child Development, 51, 529-544.

Chorpita, B. F. (2001). Control and the development of negative emotion. In Vasey, M. W., Dadds, M. R., (Eds.) The developmental psychopathology of anxiety. New York, NY, US: Oxford University Press, pp. 112-142.

Chrystan, J. A. (2005). Social anxiety in college students: The interaction of parental control and proximity. Unpublished master's thesis, West Virginia University.

Clark, D. A., Steer, R. A., Beck, A. T., \& Ross, L. (1995). Psychometric characteristics of revised sociotropy and autonomy scales in college students. Behavior Research and Therapy, 33, 325334. 
Clark, D. A., Turner, S. M., Beidel, D. C., Donovan, J. E., Kirisci, L., Jacob, R.G. (1994). Reliability and Validity of the Social Phobia and Anxiety Inventory for Adolescents. Psychological Assessment, 6, 135-140.

Cohen, S., Hoberman, H. M. (1983). Positive events and social supports as buffers of life change stress. Journal of Applied Social Psychology, 13, 99-125.

Dozois, J. A., Dobson, K. S., \& Ahnberg, J. L. (1998). A psychometric evaluation of the Beck Depression Inventory-II. Psychological Assessment, 10, 83-89.

Erickson, M. F., Sroufe, L. A., \& Egeland, B. (1985). The relationship between quality of attachment and behavior problems in a high-risk sample. Monographs of the Society for Research in Child Development, 50 (1-2) Serial No. 209), 147-166.

Garcia-Coll, C., Kagan, J., \& Reznick, J. S. (1984). Behavioral Inhibition in young children. Child Development, 55, 1005-1019.

Ginsburg, G. S., La Greca, A. M., \& Silverman, W. K. (1998). Social anxiety in children with anxiety disorders: Relation with social and emotional functioning. Journal of Abnormal Child Psychology, 26, 175-185.

Ginsburg, G.S., Siqueland, L., Masia-Warner, C., Hedtke, K. A. (2004). Anxiety disorders in children: Family matters. Cognitive and Behavioral Practice, 11, 28-43.

Greco, L. A., \& Morris, T. L. (2002). Paternal child-rearing style and child social anxiety: Investigation of child perceptions and actual father behavior. Journal of Psychopathology and Behavioral Assessment, 24, 259-267.

Greco, L. A., \& Morris, T. L. (2005). Factors influencing the link between social anxiety and peer acceptance: Contributions of social skills and close friendships during middle childhood. Behavior Therapy, 36 197-205. 
Heiss, G. E., Berman, W. H., Sperling, M. B. (1994). Five scales in search of a construct: Exploring continued attachment to parents in college students. Journal of Personality Assessment, 67, 102115.

Hirshfeld, D. R., Rosenbaum, J. F., Biederman, J., Bolduc, E. A., Faraone, S. V., Snidman, N., Reznick, J. S., \& Kagan, J. (1992). Stable inhibition and its association with anxiety disorder. Journal of the American Academy of Child and Adolescent Psychiatry, 31, 103-111.

Holmbeck, G. N. (1997). Toward terminological, conceptual, and statistical clarity in the study of mediators and moderators: Examples from the child-clinical and pediatric psychology literatures. Journal of consulting and Clinical Psychology, 65, 599-610.

Hudson, J. L., Rapee, R. M. (2001). Parent-child interactions and anxiety disorders: an observational study. Behaviour Research and Therapy, 39, 1411-1427.

Hudson, J. L., Rapee, R. M. (2002). Parent-child interactions in clinically anxious children and their siblings. Journal of Clinical Child and Adolescent Psychology, 31, 548-555.

Kagan, J., Reznick, J. S., \& Snidman, N. (1988). The temperamental qualities of inhibition and lack of inhibition. In M. Lewis \& S. M. Miller (Eds.), Handbook of developmental psychopathology (pp. 219-226). New York: Plenum.

Kearney, C. A., \& Silverman, W. K. (1990). A preliminary analysis of a functional model of assessment and treatment for school refusal behavior. Behavior Modification, 14, 340-366.

Kobak, R., Sudler, N., \& Gamble, W. (1991). Attachment and depressive symptoms in adolescence: A developmental pathways analysis. Development and Psychopathology, 3, 461-474.

Krohne, H. W., Hock, M. (1991). Relationships between restrictive mother-child interactions and anxiety of the child. Anxiety Research, 4, 109-124.

La Greca, A. M., Lopez, N. (1998). Social Anxiety Among Adolescents: Linkages with peer relations and friendships. Journal of Abnormal Child Psychology, 26, 83-94. 
Lanz, M., Scabini, E., Vermulst, A., \& Gerris, J. (2001). Congruence on child rearing in families with early adolescent and middle adolescent children. International Journal of Behavioral Development, 25, 133-139.

Larose, S., Boivin, M. (1997). Structural relations among attachment working models of parents, general and specific support expectations, and personal adjustment in late adolescence. Journal of Social and Personal Relationships, 14, 579-601.

Lieb, R., Wittchen, H., Höfler, M., Fuetsch, M., Stein, M., \& Merikangas, K. (2000). Parental psychopathology parenting styles, and the risk of social phobia in offspring: A prospective longitudinal community study. Archives of General Psychiatry, 37, 859-866.

Masia, C. L., \& Morris, T. L. (1998). Parental factors associated with social anxiety: Methodological limitations and suggestions for integrated behavioral research. Clinical Psychology Science and Practice, 5, 211-228.

Massey, C. J. (2000). Parent and sibling relationship influences on late adolescent social anxiety and other adjustment outcomes. Unpublished doctoral dissertation, West Virginia University.

Morris, T. L. (2001). Social phobia. In M. W. Vasey \& M. R. Dadds (Eds.), The developmental psychopathology of anxiety (pp. 435-458). Oxford: University Press.

Osman, A., Barrios, F. X., Aukes, D., Osman, J. R. (1995). Psychometric evaluation of the Social Phobia and Anxiety Inventory in college students. Journal of Clinical Psychology, 51, 235-243.

Parker, G. (1990). The Parental Bonding Instrument: A decade of research. Social Psychiatry and Psychiatric Epidemiology, 25, 281-282.

Parker, G., Tupling, H., \& Brown, L. B. (1979). A Parental Bonding Instrument. British Journal of Medical Psychology, 52, 1-10.

Rapee, R. M. (1997). Potential role of childrearing practices in the development of anxiety and depression. Clinical Psychology Review, 17, 47-67. 
Rapee, R. M., (2001). The development of generalized anxiety. In M. W. Vasey, M. R. Dadds (Eds), The developmental psychopathology of anxiety (pp. 481-503). New York: oxford University Press.

Spence, S. H., Donovan, C., \& Brechman-Toussaint, M. (1999). Social skills, social outcomes, and cognitive features of childhood social phobia. Journal of Abnormal Psychology, 108, 211-221.

Sroufe, L. A. (1979). The coherence of individual development: Early care, attachment, and subsequent developmental issues. American Psychologist, 34, 834-841.

Stark, K. D., Humphrey, L. L., Cook, K., \& Lewis, K. (1990). Perceived family environments of depressed and anxious children: Child's and maternal figures. Journal of Abnormal Child Psychology, 18, 527-547.

Turner, S. M., Beidel, D. C. (1989). Social phobia: Clinical syndrome, diagnosis, and Comorbidity. Clinical Psychology Review, 9, 3-18.

Turner, S. M., Beidel, D. C., Dancu, C. V., \& Stanley, M. A. (1989). An empirically derived inventory to measure social fears and anxiety: The Social Phobia and anxiety Inventory. Psychological Assessment, 1, 35-40.

Turner, S. M., Beidel, D. C., Roberson-Nay, R. (2005). Offspring of anxious parents: Reactivity, habituation and anxiety-proneness. Behaviour Research and Therapy, 43, 1263-1279.

Turner, S. M., Beidel, D. C., Roberson-Nay, R., Tervo, K. (2003). Parenting behaviors in parents with anxiety disorders. Behaviour Research and Therapy, 41, 541-554.

Wood, J. J., McLeod, B. D., Sigman, M., Hwang, W., Chu, B. C. (2003). Parenting and childhood anxiety: theory, empirical findings, and future directions. Journal of Child Psychology and Psychiatry, 44, 134-151. 


\section{Appendix A}

Please check the answers that apply to you and fill in all answer spaces:

1. Gender:

_ (1) Male

2. Age:

(2) Female

3. Ethnic Group:

_ (1) Caucasian (non Hispanic)

_ (5) Asian American

(2) Caucasian (Hispanic)

(6) American Indian

(3) African American (non Hispanic)

(4) African American (Hispanic)

(7) Multiracial

(8) Other

4. Status in College:
- (1) Freshman
_(3) Junior

(2) Sophomore

(4) Senior

5. Who do you consider to be your primary maternal figure?

_ (1) Biological Mother _ (3) Grandmother

(2) Stepmother _ _ (4) Other (describe)

6. How many years did you live with your primary maternal figure between the ages of birth through the present?
(1) 0 years
(2) $1-5$ years
(5) $16-18$ years
(3) 6 -10 years
(6) $19-20$ years
(4) $11-15$ years
(7) 21-22 years
(8) more than 22 years

7. Who do you consider to be your primary paternal figure?
_ (1) Biological Father
(3) Grandfather
(2) Stepfather
(4) Other (describe)

8. How many years did you live with your primary paternal figure between the ages of birth through the present?

- (1) 0 years

_- (5) 16-18 years

(2) $1-5$ years

(3) 6-10 years

— (6) 19-20 years

(4) $11-15$ years

(7) 21-22 years

(8) more than 22 years

9. Are you aware of any type of mental health concern(s) that your primary maternal figure experienced during your childhood?
(1) No
(2) Yes

10. If yes, check all mental health concerns applicable to that person:

(1) Depression

(2) Excessive worry and anxiety

(3) Anxiety in social situations

(4) Panic Attacks

(5) Alcohol Abuse

(6) Thoughts about suicide

(7) Other (describe) 
11. Are you aware of any type of mental health concern(s) that your primary paternal figure experienced during your childhood?
(1) Yes
(2) No

12. If yes, check all mental health concerns applicable to that person:
(1) Depression
(2) Excessive worry and anxiety
(3) Anxiety in social situations
(4) Panic Attacks

(5) Alcohol Abuse

(6) Thoughts about suicide

(7) Other (describe)

13. Your relationship status:
(1) Single
(2) Married
(4) Separated
(5) Divorced

(3) Live-in partner

14. How far is WVU from the home you lived in most prior to attending WVU in terms of travel time?
(1) Less than 30 minutes
(4) 3-6 hours
(2) 30 minutes -1 hour
(5) 6-9 hours
(3) 1-3 hours
(6) more than 9 hours

15. Which of the following reasons most influenced your decision to attend college at WVU?

(1) cost

(2) Academic reputation

(3) Rejection from my school of choice

(4) I wanted to attend school with my friends/significant other

(5) WVU is far away from home

16. What is the highest level of education your primary maternal figure completed?

(1) Middle School/Junior High

(2) High School/GED

(3) Some College

(4) Associate's (two year) degree

(5) Bachelor's (four year) Degree or higher

(5) Other/Unknown

17. What is the highest level of education your primary paternal figure completed?

(1) Middle School/Junior High

(2) High School/GED

(3) Some College

(4) Associate's (two year) degree

(5) Bachelor's (four year) Degree or higher

(5) Other/Unknown 
Dear Potential Research Participant:

Appendix B

You are being asked to participate in this research being conducted by Andrea M. Jones, B.A. at West Virginia University. You were selected based on your enrollment in an undergraduate psychology course at WVU. This research is being conducted to fulfill the requirements for a master's thesis in Psychology in the Department of Psychology at West Virginia University, under the supervision of Tracy Morris, Ph.D.

The purpose of this study is to learn more about adjustment in college students. A total of approximately 500 participants are expected to participate in this study.

This study consists of three sessions lasting approximately 30 minutes each (spaced approximately 4-6 weeks apart). During each session you will be asked to fill out a questionnaire regarding several individual characteristics and characteristics about your family. To remind you of future testing sessions, you will receive an automated email generated by SONA containing the date during which you can complete the next session.

There are no known or expected risks from participating in this study, except for mild frustration associated with answering several questionnaires. A list containing the contact information for mental health resources within the Morgantown area will be provided at the end of the study should you experience any frustration or distress associated with completing the questionnaires.

You will receive extra credit for your participation in this research project; however, your participation is not required for successful completion of the undergraduate course for which you are enrolled.

Any information about you that is obtained as a result of your participation in this research will be kept as confidential as legally possible. It should be noted that no identifying information will be stored with your data.

Participation is voluntary; however, you must be at least 18 years of age to participate in the study. You are free to withdraw from at any time. You may also choose not to answer any question(s) you do not wish to answer for any reason. Refusal to participate or withdrawal will not affect your class standing or grades and will involve no penalty to you. West Virginia University’s Acknowledgement is on file.

In the event you have any questions or concerns related to this research, you should contact Dr. Tracy Morris at (304) 293-2001 extension 31670 or by email at tracy.morris@mail.wvu.edu.

Thank you,

Andrea M. Jones, B.A.

Tracy L. Morris, PhD

1124 Life Sciences Building

Department of Psychology

West Virginia University

Morgantown, WV 26506-6040 
Table 1.

Psychometric Properties of Independent and Dependent Variables

\begin{tabular}{|c|c|c|c|c|}
\hline Variable & $\begin{array}{c}\text { Internal Consistency: } \\
\text { Phase I }\end{array}$ & $\begin{array}{c}\text { Internal Consistency: } \\
\text { Phase II }\end{array}$ & $\begin{array}{c}\text { Internal Consistency: } \\
\text { Phase III }\end{array}$ & $\begin{array}{l}\text { Test-Retest } \\
\text { Reliability }\end{array}$ \\
\hline \multicolumn{5}{|c|}{ Continued Attachment Scale } \\
\hline Mother & .86 & .79 & .89 & $.88^{* *}$ \\
\hline Father & .94 & .94 & .89 & $.91^{* *}$ \\
\hline \multicolumn{5}{|c|}{ Parental Bonding Instrument: Mother } \\
\hline Care & .91 & .93 & .93 & $.82 * *$ \\
\hline Protection & .89 & .90 & .89 & $.82 * *$ \\
\hline \multicolumn{5}{|c|}{ Parental Bonding Instrument: Father } \\
\hline Care & .96 & .97 & .97 & $.94 * *$ \\
\hline Protection & .85 & .90 & .89 & $.83^{* *}$ \\
\hline \multicolumn{5}{|c|}{ Inventory of Parent and Peer Attachment } \\
\hline \multicolumn{5}{|l|}{ Trust } \\
\hline Mother & .90 & .80 & .91 & $.85^{* *}$ \\
\hline Father & .92 & .87 & .88 & $.93 * *$ \\
\hline Peer & .93 & .84 & .90 & $.75 * *$ \\
\hline
\end{tabular}

$*_{p}<.05 \quad * * p<.01$ 
Table 1 (continued).

\begin{tabular}{|c|c|c|c|c|}
\hline Variable & $\begin{array}{c}\text { Internal Consistency: } \\
\text { Phase I } \\
\end{array}$ & $\begin{array}{c}\text { Internal Consistency: } \\
\text { Phase II }\end{array}$ & $\begin{array}{c}\text { Internal Consistency: } \\
\text { Phase III }\end{array}$ & $\begin{array}{l}\text { Test-Retest } \\
\text { Reliability }\end{array}$ \\
\hline \multicolumn{5}{|c|}{$\begin{array}{l}\text { Inventory of Parent and Peer Attachment } \\
\text { (continued) }\end{array}$} \\
\hline \multicolumn{5}{|l|}{ Alienation } \\
\hline Mother & .85 & .86 & .90 & $.75^{* *}$ \\
\hline Father & .90 & .90 & .90 & $.86^{* *}$ \\
\hline Peer & .63 & .66 & .64 & $.64^{* *}$ \\
\hline \multicolumn{5}{|l|}{ Communication } \\
\hline Mother & .95 & .85 & .86 & $.91^{* *}$ \\
\hline Father & .96 & .84 & .85 & $.92 * *$ \\
\hline Peer & .93 & .94 & .93 & $.83^{* *}$ \\
\hline \multicolumn{5}{|c|}{ Social Phobia and Anxiety Inventory } \\
\hline Social Phobia & .97 & .98 & .98 & $.64^{* *}$ \\
\hline Agoraphobia & .95 & .95 & .99 & $.72^{* *}$ \\
\hline Difference Score & & & & $.37 *$ \\
\hline
\end{tabular}

${ }^{*} p<.05 \quad * * p<.01$ 
Table 1 (continued).

\begin{tabular}{|c|c|c|c|c|}
\hline Variable & $\begin{array}{c}\text { Internal Consistency: } \\
\text { Phase I }\end{array}$ & $\begin{array}{c}\text { Internal Consistency: } \\
\text { Phase II }\end{array}$ & $\begin{array}{c}\text { Internal Consistency: } \\
\text { Phase III }\end{array}$ & $\begin{array}{l}\text { Test-Retest } \\
\text { Reliability }\end{array}$ \\
\hline \multicolumn{5}{|c|}{ Revised Sociotropy and Autonomy Scale } \\
\hline Sociotropy & .87 & .91 & .88 & $.77^{* *}$ \\
\hline Solitude & .63 & .75 & .67 & $.51 * *$ \\
\hline Independence & .78 & .88 & .83 & $.51 * *$ \\
\hline \multicolumn{5}{|c|}{ Interpersonal Support Evaluation List } \\
\hline Tangible & .74 & .71 & .83 & $.57 * *$ \\
\hline Appraisal & .78 & .65 & .71 & .27 \\
\hline Self-esteem & .59 & .73 & .60 & $.70 * *$ \\
\hline Belonging & .69 & .74 & .63 & .30 \\
\hline Beck Depression Inventory & .88 & .95 & .97 & $.68^{* *}$ \\
\hline Beck Anxiety Inventory & .91 & .96 & .93 & $.50 * *$ \\
\hline
\end{tabular}

${ }^{*} p<.05 \quad * * p<.01$ 
Table 2.

Participant Demographics

$\begin{array}{lll}\text { Characteristic } & \text { Frequency } & \text { Percentage }\end{array}$

Gender

Male

Female

Status in College

Freshman

13

12

8

6

11

28.2

28

71.8

Sophomore

Junior

Senior

Ethnic Group Identity

Caucasian (non Hispanic)

Caucasian (Hispanic)

Other
34

1

4
87.2

2.6

33.3

30.8

20.5

15.4

10.3

(table continues) 
Table 2 (continued).

Characteristic

Frequency

Percentage

Relationship Status

Single

34

87.2

Live-in Partner

4

10.3

Married

1

Maternal Education Level

Some College

Associate’s (two year) degree

10.3

Bachelor’s (four year) degree

13

33.3

High School/GED

15

38.5

Other/Unknown

Paternal Education Level

Some College

Associate's (two year) degree

Bachelor's (four year) degree

High School/GED

Middle School/Junior High

1

2.6

Other/Unknown

4

10.3

(table continues) 
Table 2 (continued).

\begin{tabular}{lcc}
\hline Characteristic & Frequency & Percentage \\
\hline Maternal Mother & 38 & 97.4 \\
Biological Mother & 1 & 2.6 \\
Grandmother & 35 & 89.7 \\
Paternal Father & 1 & 2.6 \\
Biological Father & 1 & 2.6 \\
Grandfather & 2 & 5.1 \\
Stepfather & & \\
Other & & \\
\hline
\end{tabular}


Table 3.

Descriptive Statistics for Dependent and Independent Variables at Phase I

\begin{tabular}{|c|c|c|c|c|}
\hline Variable & $\mathrm{N}$ & $\mathrm{M}$ & SD & Range \\
\hline \multicolumn{5}{|c|}{ Continued Attachment Scale (CAS) } \\
\hline Mother & 39 & 21.37 & 5.05 & $8-30$ \\
\hline Father & 39 & 17.78 & 6.89 & $6-30$ \\
\hline \multicolumn{5}{|c|}{$\begin{array}{l}\text { Parental Bonding Instrument: Mother } \\
\text { (PBIM) }\end{array}$} \\
\hline Care & 39 & 30.23 & 5.87 & $12-36$ \\
\hline Protection & 39 & 11.87 & 7.36 & $0-36$ \\
\hline \multicolumn{5}{|c|}{$\begin{array}{l}\text { Parental Bonding Instrument: Father } \\
\text { (PBIF) }\end{array}$} \\
\hline Care & 38 & 21.29 & 9.98 & 3-35 \\
\hline Protection & 38 & 12.08 & 6.67 & $0-29$ \\
\hline \multicolumn{5}{|c|}{$\begin{array}{l}\text { Inventory of Parent and Peer Support } \\
\text { (IPPA) }\end{array}$} \\
\hline \multicolumn{5}{|l|}{ Trust } \\
\hline Mother & 39 & 38.82 & 6.18 & $16-45$ \\
\hline Father & 37 & 32.86 & 8.92 & $11-45$ \\
\hline Peer & 39 & 37.72 & 6.21 & $22-45$ \\
\hline \multicolumn{5}{|l|}{ Alienation } \\
\hline Mother & 39 & 30.46 & 7.87 & $9-40$ \\
\hline Father & 37 & 26.49 & 6.16 & $12-36$ \\
\hline Peer & 39 & 25.59 & 3.83 & $18-33$ \\
\hline
\end{tabular}

(table continues) 
Table 3 (continued).

\begin{tabular}{|c|c|c|c|c|}
\hline Variable & $\mathrm{N}$ & M & SD & Range \\
\hline \multicolumn{5}{|l|}{ Communication } \\
\hline Mother & 39 & 30.46 & 7.87 & $9-40$ \\
\hline Father & 37 & 23.97 & 6.97 & $12-36$ \\
\hline Peer & 39 & 34.72 & 7.32 & $16-45$ \\
\hline \multicolumn{5}{|l|}{$\begin{array}{l}\text { Social Phobia and Anxiety Inventory } \\
\text { (SPAI) }\end{array}$} \\
\hline Social Phobia & 39 & 65.67 & 17.45 & 20-114 \\
\hline Agoraphobia & 39 & 32.82 & 10.17 & $6-57$ \\
\hline Difference Score & 39 & 32.84 & 12.72 & $8-63$ \\
\hline \multicolumn{5}{|c|}{$\begin{array}{l}\text { Revised Sociotropy and Autonomy Scale } \\
\text { (SAS-R) }\end{array}$} \\
\hline Sociotropy & 39 & 92.90 & 15.53 & $60-130$ \\
\hline Solitude & 39 & 33.56 & 5.99 & $18-46$ \\
\hline Independence & 39 & 59.67 & 8.18 & $41-81$ \\
\hline \multicolumn{5}{|l|}{$\begin{array}{l}\text { Interpersonal Support Evaluation List } \\
\text { (ISEL) }\end{array}$} \\
\hline Tangible & 38 & 10.18 & 2.18 & $2-12$ \\
\hline Appraisal & 38 & 9.05 & 2.61 & $0-12$ \\
\hline Self-esteem & 38 & 8.02 & 2.25 & $4-12$ \\
\hline Belonging & 38 & 7.95 & 2.60 & $2-12$ \\
\hline Total & 38 & 35.21 & 7.56 & $9-46$ \\
\hline Beck Depression Inventory (BDI) & 39 & 12.26 & 8.71 & $0-32$ \\
\hline Beck Anxiety Inventory (BAI) & 39 & 9.87 & 8.59 & $0-35$ \\
\hline
\end{tabular}


Table 4.

Descriptive Statistics for Dependent and Independent Variables at Phase II

\begin{tabular}{|c|c|c|c|c|}
\hline Variable & $\mathrm{N}$ & $\mathrm{M}$ & SD & Range \\
\hline \multicolumn{5}{|c|}{ Continued Attachment Scale (CAS) } \\
\hline Mother & 39 & 20.66 & 4.86 & $7-30$ \\
\hline Father & 39 & 17.33 & 6.51 & $7-30$ \\
\hline \multicolumn{5}{|c|}{$\begin{array}{l}\text { Parental Bonding Instrument: Mother } \\
\text { (PBIM) }\end{array}$} \\
\hline Care & 39 & 29.44 & 6.47 & $13-36$ \\
\hline Protection & 39 & 11.77 & 7.47 & $0-36$ \\
\hline \multicolumn{5}{|c|}{$\begin{array}{l}\text { Parental Bonding Instrument: Father } \\
\text { (PBIF) }\end{array}$} \\
\hline Care & 38 & 22.58 & 10.37 & $0-36$ \\
\hline Protection & 38 & 12.92 & 7.83 & $0-31$ \\
\hline \multicolumn{5}{|c|}{$\begin{array}{l}\text { Inventory of Parent and Peer Support } \\
\text { (IPPA) }\end{array}$} \\
\hline \multicolumn{5}{|l|}{ Trust } \\
\hline Mother & 39 & 39.08 & 5.45 & $25-45$ \\
\hline Father & 37 & 34.05 & 9.16 & $10-45$ \\
\hline Peer & 39 & 37.85 & 6.46 & $22-45$ \\
\hline \multicolumn{5}{|l|}{ Alienation } \\
\hline Mother & 39 & 29.23 & 4.40 & $20-36$ \\
\hline Father & 37 & 26.59 & 6.27 & $12-36$ \\
\hline Peer & 39 & 25.18 & 4.38 & $15-33$ \\
\hline
\end{tabular}

(table continues) 
Table 4 (continued).

\begin{tabular}{|c|c|c|c|c|}
\hline Variable & $\mathrm{N}$ & M & SD & Range \\
\hline \multicolumn{5}{|l|}{ Communication } \\
\hline Mother & 39 & 31.28 & 7.52 & $13-40$ \\
\hline Father & 37 & 25.11 & 9.78 & $8-40$ \\
\hline Peer & 39 & 35.23 & 7.62 & $19-45$ \\
\hline \multicolumn{5}{|l|}{$\begin{array}{l}\text { Social Phobia and Anxiety Inventory } \\
\text { (SPAI) }\end{array}$} \\
\hline Social Phobia & 39 & 56.90 & 21.27 & $12-141$ \\
\hline Agoraphobia & 39 & 27.51 & 11.68 & $3-61$ \\
\hline Difference Score & 39 & 29.38 & 12.41 & $0-60$ \\
\hline \multicolumn{5}{|c|}{$\begin{array}{l}\text { Revised Sociotropy and Autonomy Scale } \\
\text { (SAS-R) }\end{array}$} \\
\hline Sociotropy & 38 & 89.95 & 17.79 & $58-120$ \\
\hline Solitude & 38 & 34.03 & 6.88 & $21-49$ \\
\hline Independence & 38 & 59.39 & 10.83 & $37-84$ \\
\hline \multicolumn{5}{|l|}{$\begin{array}{l}\text { Interpersonal Support Evaluation List } \\
\text { (ISEL) }\end{array}$} \\
\hline Tangible & 39 & 10.28 & 2.06 & $4-12$ \\
\hline Appraisal & 39 & 8.69 & 2.40 & $0-11$ \\
\hline Self-esteem & 39 & 7.38 & 2.65 & $0-12$ \\
\hline Belonging & 39 & 8.05 & 2.83 & $1-12$ \\
\hline Total & 39 & 34.41 & 7.54 & $17-46$ \\
\hline Beck Depression Inventory (BDI) & 39 & 12.82 & 11.07 & $0-38$ \\
\hline Beck Anxiety Inventory (BAI) & 39 & 8.69 & 9.71 & $0-36$ \\
\hline
\end{tabular}


Table 5.

Descriptive Statistics for Dependent and Independent Variables at Phase III

\begin{tabular}{lrrrr}
\hline Variable & N & M & SD & Range \\
\hline Continued Attachment Scale (CAS) & & & & \\
Mother & 39 & 20.36 & 5.17 & $8-29$ \\
Father & 38 & 17.26 & 6.68 & $6-30$
\end{tabular}

Parental Bonding Instrument: Mother (PBIM)
Care
Protection
Parental Bonding Instrument: Father

39

29.79

6.40

13-36

39

11.36

6.82

$0-26$ (PBIF)
Care
Protection
Inventory of Parent and Peer Support

38

22.87

10.38

0-36

38

11.03

6.77

0-28 (IPPA)

Trust

$\begin{array}{llllr}\text { Mother } & 38 & 38.66 & 6.51 & 24-45 \\ \text { Father } & 36 & 33.42 & 9.28 & 9-45 \\ \text { Peer } & 38 & 37.58 & 6.45 & 23-45\end{array}$

Alienation

$\begin{array}{lcccc}\text { Mother } & 38 & 29.44 & 6.61 & 14-40 \\ \text { Father } & 36 & 25.94 & 5.65 & 14-36 \\ \text { Peer } & 39 & 25.05 & 5.34 & 2-34\end{array}$

(table continues) 
Table 5 (continued).

\begin{tabular}{|c|c|c|c|c|}
\hline Variable & $\mathrm{N}$ & M & SD & Range \\
\hline \multicolumn{5}{|l|}{ Communication } \\
\hline Mother & 38 & 30.76 & 7.66 & $9-40$ \\
\hline Father & 36 & 25.42 & 9.34 & $8-40$ \\
\hline Peer & 39 & 34.33 & 7.94 & $14-45$ \\
\hline \multicolumn{5}{|l|}{$\begin{array}{l}\text { Social Phobia and Anxiety Inventory } \\
\text { (SPAI) }\end{array}$} \\
\hline Social Phobia & 39 & 54.49 & 24.83 & $14-132$ \\
\hline Agoraphobia & 39 & 25.33 & 12.87 & $0-66$ \\
\hline Difference Score & 39 & 29.15 & 14.42 & $6-66$ \\
\hline \multicolumn{5}{|c|}{$\begin{array}{l}\text { Revised Sociotropy and Autonomy Scale } \\
\text { (SAS-R) }\end{array}$} \\
\hline Sociotropy & 38 & 89.71 & 13.90 & $60-129$ \\
\hline Solitude & 38 & 34.76 & 5.55 & $22-46$ \\
\hline Independence & 38 & 57.95 & 8.40 & $43-78$ \\
\hline \multicolumn{5}{|l|}{$\begin{array}{l}\text { Interpersonal Support Evaluation List } \\
\text { (ISEL) }\end{array}$} \\
\hline Tangible & 38 & 10.16 & 2.47 & $4-12$ \\
\hline Appraisal & 38 & 9.58 & 2.42 & $4-12$ \\
\hline Self-esteem & 38 & 7.42 & 2.29 & $4-12$ \\
\hline Belonging & 38 & 8.83 & 2.47 & $3-12$ \\
\hline Total & 39 & 35.68 & 7.81 & $21-46$ \\
\hline Beck Depression Inventory (BDI) & 37 & 14.19 & 14.49 & $0-62$ \\
\hline Beck Anxiety Inventory (BAI) & 38 & 10.45 & 13.04 & $0-63$ \\
\hline
\end{tabular}


Table 6.

Correlations of Independent and Dependent Variables at Phase I

\begin{tabular}{|c|c|c|c|c|c|c|c|c|c|c|c|c|}
\hline & 1 & 2 & 3 & 4 & 5 & 6 & 7 & 8 & 9 & 10 & 11 & 12 \\
\hline 1. CAS-M & & $.72^{* *}$ & .12 & $.54 *$ & .07 & $.62 * *$ & $.42^{* *}$ & $.54^{* *}$ & $.34 *$ & $.65^{* *}$ & $.56^{* *}$ & $.39 *$ \\
\hline 2. CAS-F & & & .08 & .24 & .05 & $.73^{* *}$ & .10 & $.78^{* *}$ & .19 & $.33^{*}$ & $.77^{* *}$ & .23 \\
\hline 3. PBI-M/Protection & & & & -.27 & $.63^{* *}$ & -.24 & $-.59 * *$ & -.28 & $-.37 *$ & -.20 & -.16 & $-.35^{*}$ \\
\hline 4. PBI-M/Care & & & & & -.12 & .27 & $.76^{* *}$ & .18 & .27 & $.80 * *$ & .17 & $.33^{*}$ \\
\hline 5. PBI-F/Protection & & & & & & -.31 & $-.36 *$ & -.32 & -.05 & -.11 & -.23 & -.07 \\
\hline 6. PBI-F/Care & & & & & & & .27 & $.91^{* *}$ & $.33^{*}$ & $.36 *$ & $.91^{* *}$ & .29 \\
\hline 7. IPPA-M/Trust & & & & & & & & .27 & $.43^{* *}$ & $.79 * *$ & .18 & $.48^{* *}$ \\
\hline 8. IPPA-F/Trust & & & & & & & & & $.39 *$ & .32 & $.89 * *$ & $.37 *$ \\
\hline 9. IPPA-P/Trust & & & & & & & & & & $.40 *$ & $.39 *$ & $.88^{* *}$ \\
\hline 10. IPPA-M/Communication & & & & & & & & & & & $.38 *$ & $.50^{* *}$ \\
\hline 11. IPPA-F/Communication & & & & & & & & & & & & $.36^{*}$ \\
\hline 12. IPPA-P/Communication & & & & & & & & & & & & \\
\hline
\end{tabular}

$* p<.05 * * p<.01$

(table continues) 
Table 6 (continued).

\begin{tabular}{|c|c|c|c|c|c|c|c|c|c|c|c|c|c|}
\hline & 13 & 14 & 15 & 16 & 17 & 18 & 19 & 20 & 21 & 22 & 23 & 24 & 25 \\
\hline 1. CAS-M & .30 & $.59 * *$ & .14 & .01 & $.36^{*}$ & $.34^{*}$ & .28 & $.59 * *$ & .19 & -.14 & .12 & -.28 & -.08 \\
\hline 2. CAS-F & .30 & $.59 * *$ & .14 & .01 & .36 & $.34 *$ & .23 & $.50 * *$ & .12 & -.13 & -.08 & -.30 & -.21 \\
\hline 3. PBI-M/Protection & $-.37 *$ & -.27 & $-.33^{*}$ & -.03 & -.30 & -.03 & -.07 & -.05 & -.09 & .29 & .06 & .23 & -.11 \\
\hline 4. PBI-M/Care & $.73^{* *}$ & .29 & .24 & -.04 & $.33^{*}$ & .31 & .23 & $.50 * *$ & .17 & -.13 & .12 & $-.34 *$ & -.11 \\
\hline 5. PBI-F/Protection & $-.33^{*}$ & $-.38 *$ & -.18 & -.12 & -.30 & .08 & .06 & .08 & .15 & -.08 & .10 & .20 & -.05 \\
\hline 6. PBI-F/Care & $.41 *$ & $.89 * *$ & $.38 *$ & .02 & $.37 *$ & .15 & .18 & $.47^{* *}$ & .08 & -.08 & -.13 & -.31 & -.17 \\
\hline 7. IPPA-M/Trust & $.71^{* *}$ & .27 & $.37 *$ & .02 & .31 & .21 & .20 & $.35 *$ & .20 & -.21 & .21 & $-.38 *$ & -.06 \\
\hline 8. IPPA-F/Trust & .39 & $.83^{* *}$ & $.39 *$ & .06 & .30 & .01 & .16 & $.33^{*}$ & .14 & .01 & -.04 & .23 & -.03 \\
\hline 9. IPPA-P/Trust & .25 & .25 & $.48^{* *}$ & .15 & .22 & .10 & .18 & .26 & $.50 * *$ & -.30 & .17 & -.09 & .21 \\
\hline 10. IPPA-M/Communication & $.72 * *$ & $.38 *$ & $.32 *$ & .02 & $.36 *$ & .29 & .23 & $.58 * *$ & .27 & -.11 & .10 & $-.48 * *$ & -.14 \\
\hline 11. IPPA-F/Communication & $.39 * *$ & $.84 * *$ & $.34 *$ & -.01 & $.33^{*}$ & .03 & .05 & $.45^{*}$ & .07 & -.10 & -.15 & $-.36 *$ & -.16 \\
\hline 12. IPPA-P/Communication & $.37 *$ & .24 & $.49 * *$ & -.03 & $.38 * *$ & .22 & .32 & .27 & $.52 * *$ & $-.32 *$ & .02 & -.14 & .09 \\
\hline
\end{tabular}

${ }^{*} p<.05 \quad * * p<.01$

(table continues) 
Table 6 (continued).

\begin{tabular}{|c|c|c|c|c|c|c|c|c|c|c|c|c|c|}
\hline & 13 & 14 & 15 & 16 & 17 & 18 & 19 & 20 & 21 & 22 & 23 & 24 & 25 \\
\hline 13. IPPA-M/Alienation & & $.57 * *$ & $.56^{*}$ & -.27 & .26 & .12 & .18 & $.36^{*}$ & -.05 & -.16 & -.05 & $-.42 * *$ & -.17 \\
\hline 14. IPPA-F/Alienation & & & $.58^{* *}$ & -.15 & .28 & -.04 & .15 & .31 & -.14 & -.10 & -.09 & -.29 & -.16 \\
\hline 15. IPPA-P/Alienation & & & & $-.35 *$ & .13 & .11 & $.44^{* *}$ & .17 & -.13 & $-.36^{*}$ & .09 & -.29 & -.16 \\
\hline 16. SPAI Difference & & & & & -.31 & -.18 & -.27 & -.11 & $.41^{* *}$ & .23 & .09 & $.35 *$ & $.45^{* *}$ \\
\hline 17. ISEL/Self-Esteem & & & & & & $.44^{* *}$ & $.37 *$ & $.56 * *$ & .01 & -.10 & .12 & $-.38 *$ & -.17 \\
\hline 18. ISEL/Tangible & & & & & & & $.55^{* *}$ & $.54 * *$ & .15 & $-.38 *$ & .01 & $-.45 * *$ & $-.34 *$ \\
\hline 19. ISEL/Appraisal & & & & & & & & $.46^{* *}$ & .11 & -.23 & .09 & -.30 & -.30 \\
\hline 20. ISEL/Belonging & & & & & & & & & .14 & -.05 & .10 & $-.50 * *$ & -.32 \\
\hline 21. SAS/Sociotropy & & & & & & & & & & .13 & .16 & .14 & .14 \\
\hline 22. SAS/Solitude & & & & & & & & & & & .30 & $.41^{* *}$ & .22 \\
\hline 23. SAS/Independence & & & & & & & & & & & & .09 & .21 \\
\hline 24. Beck Depression Inventory & & & & & & & & & & & & & $.56^{* *}$ \\
\hline 25. Beck Anxiety Inventory & & & & & & & & & & & & & \\
\hline
\end{tabular}

$* p<.05 \quad * * p<.01$ 
Table 7.

Correlations of Dependent and Independent Variables at Phase II

\begin{tabular}{|c|c|c|c|c|c|c|c|c|c|c|c|c|}
\hline & 1 & 2 & 3 & 4 & 5 & 6 & 7 & 8 & 9 & 10 & 11 & 12 \\
\hline 1. CAS-M & & $.64 * *$ & -.01 & $.59^{* *}$ & .19 & $.51^{* *}$ & $.51^{* *}$ & $.57^{* *}$ & .30 & $-.47^{* *}$ & $.50^{* *}$ & $.40 *$ \\
\hline 2. CAS-F & & & -.06 & .10 & -.01 & $.66^{* *}$ & .13 & $.73 * *$ & .02 & .26 & $.78^{* *}$ & .19 \\
\hline 3. PBI-M/Protection & & & & $-.38 *$ & $.56^{* *}$ & -.27 & $-.50 *$ & -.24 & $-.35^{*}$ & $.38 *$ & -.13 & $-.33^{*}$ \\
\hline 4. PBI-M/Care & & & & & $-.36^{*}$ & .29 & $.83^{* *}$ & .27 & $.38 *$ & $-.66^{* *}$ & .20 & $.30 *$ \\
\hline 5. PBI-F/Protection & & & & & & -.28 & $-.47 * *$ & -.31 & -.17 & $.56^{* *}$ & -.17 & -.21 \\
\hline 6. PBI-F/Care & & & & & & & .27 & $.92 * *$ & .23 & $-.37^{*}$ & $.85^{* *}$ & $.37 *$ \\
\hline 7. IPPA-M/Trust & & & & & & & & .18 & $.46^{* *}$ & $.79 * *$ & .15 & $.44^{* *}$ \\
\hline 8. IPPA-F/Trust & & & & & & & & & .11 & $.31 *$ & $.90^{* *}$ & .25 \\
\hline 9. IPPA-P/Trust & & & & & & & & & & $.23^{*}$ & .15 & $.80 * *$ \\
\hline 10. IPPA-M/Communication & & & & & & & & & & & $.38 *$ & $.39 * *$ \\
\hline 11. IPPA-F/Communication & & & & & & & & & & & & .29 \\
\hline 12. IPPA-P/Communication & & & & & & & & & & & & \\
\hline
\end{tabular}

${ }^{*} p<.05 \quad * * p<.01$

(table continues) 
Table 7 (continued).

\begin{tabular}{|c|c|c|c|c|c|c|c|c|c|c|c|c|c|}
\hline & 13 & 14 & 15 & 16 & 17 & 18 & 19 & 20 & 21 & 22 & 23 & 24 & 25 \\
\hline 1. CAS-M & $-.47 * *$ & -.41 & -.19 & .01 & $.44 * *$ & $.47 * *$ & .29 & $.57 * *$ & .28 & -.15 & .22 & -.30 & -.14 \\
\hline 2. CAS-F & -.30 & $-.61^{* *}$ & .14 & -.17 & .20 & $.38 *$ & .20 & $.40 *$ & .17 & -.10 & -.02 & -.24 & -.19 \\
\hline 3. PBI-M/Protection & -.24 & .26 & .26 & -.18 & -.25 & .00 & .00 & .05 & -.07 & .28 & -.07 & .09 & .03 \\
\hline 4. PBI-M/Care & $.71^{* *}$ & -.23 & -.25 & .21 & $.41^{* *}$ & $.34^{*}$ & .22 & .23 & .23 & -.02 & .25 & -.24 & -.04 \\
\hline 5. PBI-F/Protection & $-.34 *$ & $.41^{*}$ & $-.36^{*}$ & -.09 & $-.42 * *$ & .03 & -.07 & -.05 & .10 & .00 & .01 & .23 & .18 \\
\hline 6. PBI-F/Care & $-.43 * *$ & $-.84^{* *}$ & $-.32 *$ & -.01 & .26 & .25 & .08 & $.40 *$ & .17 & -.19 & -.16 & $-.43 * *$ & -.31 \\
\hline 7. IPPA-M/Trust & $.63^{* *}$ & .15 & $.33 *$ & .06 & $.45^{* *}$ & $.41 * *$ & .25 & .27 & .14 & -.17 & -.20 & -.31 & -.10 \\
\hline 8. IPPA-F/Trust & .28 & $.84 * *$ & .26 & .04 & $.26^{*}$ & .24 & .07 & $.38 *$ & .18 & -.12 & -.09 & $-.34 *$ & -.31 \\
\hline 9. IPPA-P/Trust & .20 & .07 & $.58^{* *}$ & .03 & $.46^{* *}$ & .31 & .24 & $.38 *$ & .29 & -.32 & .19 & -.11 & .06 \\
\hline 10. IPPA-M/Communication & $.56^{* *}$ & .24 & -.20 & .00 & $.40^{*}$ & .31 & .20 & $.34 *$ & .19 & -.09 & .04 & $-.48 * *$ & -.23 \\
\hline 11. IPPA-F/Communication & .24 & $.75^{* *}$ & .29 & -.09 & .22 & .20 & .02 & $.44 *$ & .15 & -.10 & -.20 & -.30 & -.27 \\
\hline 12. IPPA-P/Communication & .11 & .10 & $.59 * *$ & -.12 & $.48^{* *}$ & $.49 * *$ & $.49 * *$ & $.43^{* *}$ & $.39 *$ & $-.35^{*}$ & .13 & -.32 & -.15 \\
\hline
\end{tabular}

${ }^{*} p<.05 \quad * * p<.01$

(table continues) 
Table 7 (continued).

\begin{tabular}{|c|c|c|c|c|c|c|c|c|c|c|c|c|c|}
\hline & 13 & 14 & 15 & 16 & 17 & 18 & 19 & 20 & 21 & 22 & 23 & 24 & 25 \\
\hline 13. IPPA-M/Alienation & & $.48^{* *}$ & $.52 * *$ & -.19 & .18 & .11 & .16 & .07 & -.19 & -.22 & -.10 & $-.60 * *$ & $-.50 * *$ \\
\hline 14. IPPA-F/Alienation & & & $.45^{* *}$ & -.13 & -.20 & -.09 & -.01 & .30 & -.13 & .10 &.-16 & $-.48^{* *}$ & $-.55^{* *}$ \\
\hline 15. IPPA-P/Alienation & & & & -.43 & -.22 & -.30 & $.48^{* *}$ & $.36^{*}$ & -.20 & -.24 & -.04 & $-.50 * *$ & $-.50 * *$ \\
\hline 16. SPAI Difference & & & & & .04 & -.11 & -.30 & -.23 & $.62^{* *}$ & $.37^{*}$ & $.35 *$ & $.48 * *$ & $.55 * *$ \\
\hline 17. ISEL/Self-Esteem & & & & & & $.44^{* *}$ & .23 & $.40 *$ & .12 & -.19 & $.47^{* *}$ & -.21 & -.02 \\
\hline 18. ISEL/Tangible & & & & & & & $.69 * *$ & $.52 * *$ & $.36^{*}$ & -.19 & $.39 *$ & -.29 & -.20 \\
\hline 19. ISEL/Appraisal & & & & & & & & $.39 *$ & .21 & -.25 & .26 & $-.42 * *$ & $-.33^{*}$ \\
\hline 20. ISEL/Belonging & & & & & & & & & .23 & -.14 & .20 & -.29 & -.16 \\
\hline 21. SAS/Sociotropy & & & & & & & & & & .15 & .22 & .13 & .28 \\
\hline 22. SAS/Solitude & & & & & & & & & & & .24 & $.47 * *$ & .30 \\
\hline 23. SAS/Independence & & & & & & & & & & & & .23 & .31 \\
\hline 24. Beck Depression Inventory & & & & & & & & & & & & & $.80 * *$ \\
\hline 25. Beck Anxiety Inventory & & & & & & & & & & & & & \\
\hline
\end{tabular}

${ }^{*} p<.05 \quad * * p<.01$ 
Table 8.

Correlations of Independent and Dependent Variables at Phase III.

\begin{tabular}{|c|c|c|c|c|c|c|c|c|c|c|c|c|}
\hline & 1 & 2 & 3 & 4 & 5 & 6 & 7 & 8 & 9 & 10 & 11 & 12 \\
\hline 1. CAS-M & & $.60^{* *}$ & $-.03 *$ & $.59 * *$ & .18 & $.56^{* *}$ & $.52 * *$ & $.50 * *$ & .23 & $.73^{* *}$ & $.52 * *$ & $.36 *$ \\
\hline 2. CAS-F & & & .10 & .13 & -.08 & $.65^{* *}$ & .12 & $.66^{* *}$ & .24 & .31 & $.74^{* *}$ & $.36 *$ \\
\hline 3. PBI-M/Protection & & & & $-.35^{*}$ & $.55^{* *}$ & -.30 & $-.55^{* *}$ & $-.36 *$ & $-.44 * *$ & -.32 & -.21 & $-.45^{* *}$ \\
\hline 4. PBI-M/Care & & & & & $-.36^{*}$ & $.35 *$ & $.85 * *$ & $.37 *$ & $.36^{*}$ & $.82^{* *}$ & .27 & $.44 * *$ \\
\hline 5. PBI-F/Protection & & & & & & -.28 & $-.44 * *$ & -.28 & -.28 & -.24 & -.16 & -.30 \\
\hline 6. PBI-F/Care & & & & & & & $.34 *$ & $.92^{* *}$ & $.41^{* *}$ & $.41^{* *}$ & $.87^{* *}$ & $.50 * *$ \\
\hline 7. IPPA-M/Trust & & & & & & & & $.35 *$ & $.44^{* *}$ & $.79^{* *}$ & .24 & $.47^{* *}$ \\
\hline 8. IPPA-F/Trust & & & & & & & & & $.31 *$ & $.34 * *$ & $.90^{* *}$ & $.50 * *$ \\
\hline 9. IPPA-P/Trust & & & & & & & & & & $.34 *$ & $.37 *$ & $.88^{* *}$ \\
\hline 10. IPPA-M/Communication & & & & & & & & & & & $.41^{* *}$ & $.54 * *$ \\
\hline 11. IPPA-F/Communication & & & & & & & & & & & & $.53 * *$ \\
\hline 12. IPPA-P/Communication & & & & & & & & & & & & \\
\hline
\end{tabular}

$* p<.05 \quad * * p<.01$

(table continues) 
Table 8 (continued).

\begin{tabular}{|c|c|c|c|c|c|c|c|c|c|c|c|c|c|}
\hline & 13 & 14 & 15 & 16 & 17 & 18 & 19 & 20 & 21 & 22 & 23 & 24 & 25 \\
\hline 1. CAS-M & $-.58 * *$ & $-.51 * *$ & -.17 & $-.36^{*}$ & .16 & .12 & .10 & .16 & .04 & -.05 & .06 & -.23 & -.11 \\
\hline 2. CAS-F & $-.33 *$ & $-.65^{* *}$ & -.15 & $-.44 * *$ & .07 & .27 & .20 & .30 & .06 & -.24 & -.15 & -.22 & -.31 \\
\hline 3. PBI-M/Protection & $.46^{* *}$ & .22 & $.33 *$ & -.03 & -.23 & -.16 & -.09 & -.21 & -.05 & $.37 *$ & -.21 & .30 & .29 \\
\hline 4. PBI-M/Care & $-.73 * *$ & $-.38 *$ & $-.37 *$ & -.27 & .17 & .16 & -.01 & .11 & .00 & -.13 & .22 & $-.34 *$ & -.25 \\
\hline 5. PBI-F/Protection & $.35^{*}$ & .23 & .17 & -.19 & -.27 & -.07 & -.04 & -.11 & -.09 & .09 & -.07 & -.18 & -.30 \\
\hline 6. PBI-F/Care & $-.42 * *$ & $-.86 * *$ & $-.34 *$ & $-.33 *$ & .21 & .15 & .14 & $.37 *$ & -.01 & -.24 & -.05 & $-.44 * *$ & $-.42 * *$ \\
\hline 7. IPPA-M/Trust & $.78^{* *}$ & .30 & .32 & -.18 & .11 & .11 & -.06 & .13 & .13 & -.16 & .26 & -.33 & -.27 \\
\hline 8. IPPA-F/Trust & $.42 * *$ & $.82 * *$ & .29 & -.23 & .06 & .10 & .05 & .28 & .08 & -.16 & -.07 & $-.30 *$ & $-.37 *$ \\
\hline 9. IPPA-P/Trust & $.37^{*}$ & .16 & $.59 * *$ & -.11 & $.43^{* *}$ & $.29 *$ & $.36^{*}$ & $.44^{*}$ & $.32 *$ & $-.40^{*}$ & .31 & -.30 & -.14 \\
\hline 10. IPPA-M/Communication & $.82 * *$ & $.36^{*}$ & -.46 & $-.16^{* *}$ & .15 & .14 & .14 & .21 & -.07 & -.19 & .13 & $-.42 * *$ & -.29 \\
\hline 11. IPPA-F/Communication & $.44^{* *}$ & $-.81^{* *}$ & $-.40^{*}$ & $-.40 *$ & .03 & .11 & .11 & .25 & .01 & -.23 & -.16 & .30 & -.33 \\
\hline 12. IPPA-P/Communication & $-.43 * *$ & -.28 & $.52 * *$ & -.15 & $.44^{* *}$ & .26 & $.38^{*}$ & $.38 *$ & $.32 *$ & $-.45^{* *}$ & .25 & $-.34^{*}$ & -.25 \\
\hline
\end{tabular}

${ }^{*} p<.05 \quad * * p<.01$

(table continues) 
Table 8 (continued).

\begin{tabular}{|c|c|c|c|c|c|c|c|c|c|c|c|c|c|}
\hline & 13 & 14 & 15 & 16 & 17 & 18 & 19 & 20 & 21 & 22 & 23 & 24 & 25 \\
\hline 13. IPPA-M/Alienation & & $.56^{* *}$ & $.53^{* *}$ & $-.58 * *$ & .06 & .09 & .04 & .18 & -.27 & -.24 & -.03 & $-.46^{* *}$ & $-.48 * *$ \\
\hline 14. IPPA-F/Alienation & & & $.49^{* *}$ & $-.50 * *$ & .04 & .04 & -.01 & .18 & -.31 & -.24 & -.19 & $-.42 *$ & $-.46^{* *}$ \\
\hline 15. IPPA-P/Alienation & & & & $-.40 *$ & -.03 & .10 & .18 & .19 & -.13 & $-.33^{*}$ & -.02 & $-.38 *$ & -.30 \\
\hline 16. SPAI Difference & & & & & .04 & -.25 & -.15 & -.24 & $.51^{* *}$ & $.53^{* *}$ & .25 & $.55^{* *}$ & $.57 * *$ \\
\hline 17. ISEL/Self-Esteem & & & & & & $.38 *$ & $.40 *$ & $.47^{* *}$ & .06 & -.28 & .30 & -.25 & -.15 \\
\hline 18. ISEL/Tangible & & & & & & & $.70^{* *}$ & $.69 * *$ & .15 & $-.53^{* *}$ & $.39 *$ & $-.35 *$ & -.31 \\
\hline 19. ISEL/Appraisal & & & & & & & & $.58^{* *}$ & .09 & $-.38 *$ & .23 & -.29 & -.25 \\
\hline 20. ISEL/Belonging & & & & & & & & & .21 & $-.38^{*}$ & .23 & -.29 & -.25 \\
\hline 21. SAS/Sociotropy & & & & & & & & & & .07 & $.39 *$ & .01 & .14 \\
\hline 22. SAS/Solitude & & & & & & & & & & & -.02 & $.53^{* *}$ & $.39 *$ \\
\hline 23. SAS/Independence & & & & & & & & & & & & .20 & .02 \\
\hline 24. Beck Depression Inventory & & & & & & & & & & & & & $.84^{* *}$ \\
\hline 25. Beck Anxiety Inventory & & & & & & & & & & & & & \\
\hline
\end{tabular}

${ }^{*} p<.05 \quad * * p<.01$ 
Table 9

Correlations among Phase I Parenting Variables and Phase III Symptom Variables

\begin{tabular}{lccc}
\hline & SPAI Difference & Beck Depression Inventory & Beck Anxiety Inventory \\
\hline PBI-F/Care & -.31 & -.32 & -.31 \\
PBI-F/Protection & -.07 & .19 & .30 \\
PBI-M/Care & -.24 & -.18 & -.11 \\
PBI-M/Protection & -.04 & .26 & .22 \\
IPPA-M/Trust & -.08 & -.30 & -.20 \\
IPPA-F/Trust & -.18 & -.26 & -.32 \\
IPPA-M/Communication & $-.39^{*}$ & $-.39 *$ & -.30 \\
IPPA-F/Communication & $-.37^{*}$ & -.32 & -.35 \\
IPPA-M/Alienation & $-.37^{*}$ & $-.35^{*}$ & $-.37^{*}$ \\
IPPA-F/Alienation & $-.36^{*}$ & $-.36^{*}$ & $-.42^{*}$ \\
\hline
\end{tabular}

${ }^{*} p<.05 \quad * * p<.01$ 
Table 10

Correlations among Phase I Parenting Variables and Symptom Change Scores

\begin{tabular}{lccc}
\hline & SPAI Difference & Beck Depression Inventory & Beck Anxiety Inventory \\
\hline PBI-F/Care & -.28 & -.22 & -.25 \\
PBI-F/Protection & -.04 & .14 & $.39^{*}$ \\
PBI-M/Care & -.19 & -.01 & -.06 \\
PBI-M/Protection & -.01 & .17 & $.37^{*}$ \\
IPPA-M/Trust & -.09 & -.12 & -.20 \\
IPPA-F/Trust & -.21 & -.20 & $-.35^{*}$ \\
IPPA-M/Communication & $-.38 *$ & -.17 & -.24 \\
IPPA-F/Communication & -.32 & -.18 & -.29 \\
IPPA-M/Alienation & -.12 & -.19 & -.32 \\
IPPA-F/Alienation & -.19 & -.27 & $-.35^{*}$ \\
\hline$* p<.05 * * p<.01$ & & &
\end{tabular}


Table 11

Parenting Variables at Phase I as Predictors of Social Anxiety at Phase III

\begin{tabular}{lcccccc}
\hline & $B$ & SE $B$ & $\beta$ & $t$ & $p$ & R Square \\
& -.43 & .21 & -.31 & -2.04 & .05 & .10 \\
PBI-F/Care & -.06 & .33 & -.03 & -.19 & .85 & .00 \\
PBI-F/Protection & -.55 & .37 & -.23 & -1.50 & .14 & .05 \\
PBI-M/Care & -.06 & .30 & -.03 & -.19 & .85 & .00 \\
PBI-M/Protection & -.20 & .36 & -.09 & -.56 & .58 & .01 \\
IPPA-M/Trust & -.30 & .24 & -.20 & -1.24 & .22 & .04 \\
IPPA-F/Trust & -.72 & .26 & -.40 & -2.83 & .01 & .16 \\
IPPA-M/Communication & -.54 & .22 & -.37 & -2.43 & .02 & .13 \\
IPPA-F/Communication & -1.00 & .53 & -.29 & -1.87 & .07 & .08 \\
IPPA-M/Alienation & -.52 & .26 & -.32 & -2.02 & .05 & .10 \\
IPPA-F/Alienation & & & & & & \\
\hline
\end{tabular}

Note. Phase I social anxiety scores were controlled for when predicting phase III social anxiety from parenting variables. 
Table 12

Parenting Variables at Phase I as Predictors of Anxiety at Phase III

\begin{tabular}{lcccccc}
\hline & $B$ & $\mathrm{SE} B$ & $\beta$ & $t$ & $p$ & R Square \\
& & & & & \\
& & & & & \\
PBI-F/Care & .33 & .19 & -.26 & -1.73 & .09 & .12 \\
PBI-F/Protection & .66 & .28 & .35 & 2.38 & .02 & .00 \\
PBI-M/Care & -.15 & .33 & -.07 & -.45 & .66 & .09 \\
PBI-M/Protection & .55 & .25 & .31 & 2.20 & .03 & .03 \\
IPPA-M/Trust & -.39 & .30 & -.18 & -1.27 & .21 & .10 \\
IPPA-F/Trust & -.46 & .21 & -.32 & -2.17 & .04 & .06 \\
IPPA-M/Communication & -.39 & .23 & -.24 & -1.67 & .10 & .09 \\
IPPA-F/Communication & -.42 & .21 & -.30 & -2.01 & .05 & .09 \\
IPPA-M/Alienation & -1.00 & .44 & -.31 & -2.23 & .03 & .09 \\
IPPA-F/Alienation & -.57 & .23 & -.37 & -2.49 & .02 & .13 \\
\hline
\end{tabular}

Note. Phase I anxiety scores were controlled for when predicting phase III anxiety from parenting variables. 
Table 13

Parenting Variables at Phase I as Predictors of Depression at Phase III

\begin{tabular}{lcccccc}
\hline & $B$ & SE $B$ & $\beta$ & $t$ & $p$ & R Square \\
& -.21 & .19 & -.14 & -1.11 & .28 & .02 \\
PBI-F/Care & .18 & .28 & .08 & .65 & .52 & .01 \\
PBI-F/Protection & .09 & .32 & .04 & .27 & .79 & .00 \\
PBI-M/Care & .20 & .25 & .10 & .78 & .44 & .01 \\
PBI-M/Protection & -.12 & .31 & -.05 & -.37 & .71 & .00 \\
IPPA-M/Trust & -.22 & .21 & -.13 & -1.04 & .31 & .02 \\
IPPA-F/Trust & -.16 & .26 & -.09 & -.61 & .55 & .01 \\
IPPA-M/Communication & -.18 & .21 & -.11 & -.83 & .42 & .01 \\
IPPA-F/Communication & -.37 & .47 & -.11 & -.78 & .44 & .01 \\
IPPA-M/Alienation & -.33 & .23 & -.19 & -1.43 & .16 & .03 \\
IPPA-F/Alienation & & & & & & \\
\hline
\end{tabular}

Note. Phase I depression scores were controlled for when predicting phase III depression from parenting variables. 